\title{
Competition over piratable goods
}

\author{
Paul Belleflamme* $\quad$ Pierre M. Picard ${ }^{\dagger}$
}

December 17, 2003

\begin{abstract}
The effects of (private, small-scale) copying on the pricing behavior of producers of information goods are studied within a unified model of vertical differentiation. Although information goods are assumed to be perfectly horizontally differentiated, demands are interdependent because the copying technology exhibits increasing returns to scale. We characterize the symmetric Nash equilibria of the pricing game played by $n$ producers of information goods. We show thereby how the producers' attitudes towards piracy are interdependent and evolve with the relative attractiveness of copies.
\end{abstract}

JEL Classification Numbers: L13, L82, L86, K11, O34.

Keywords: Information goods, piracy, copyright, pricing.

*Corresponding author: CORE and IAG, Université catholique de Louvain, 34 Voie du Roman Pays, B-1348 Louvain la Neuve, Belgium (tel: +32 104782 91, fax: +32 104743 01, e-mail: belleflamme@core.ucl.ac.be, homepage: http://www.core.ucl.ac.be/ pbel/).

${ }^{\dagger}$ University of Manchester, School of Economics Studies, U.K. and CORE, Université catholique de Louvain, Belgium. 


\section{Introduction}

Information can be defined very broadly as anything that can be digitized (i.e., encoded as a stream of bits), such as text, images, voice, data, audio and video (see Varian, 1998). Information is exchanged under a wide range of formats or packages (which are not necessarily digital). These formats are generically called information goods. Books, movies, music, magazines, databases, telephone conversations, stock quotes, web pages, news, etc. all fall into this category. Most information goods are expensive to produce but cheap to reproduce. This combination of high fixed costs and low (often negligible) marginal costs implies that information goods are inherently nonrival. Moreover, because reproduction costs are also potentially very low for anybody other than the creator of the good, information goods might be nonexcludable, in the sense that one person cannot exclude another person from consuming the good in question. The degree of excludability of an information good (and hence the creator's ability to appropriate the revenues from the production of the good) can be enhanced by legal authority-typically by the adoption of laws protecting intellectual property (IP)-or by technical means (e.g., cable broadcast are encrypted, new CDs are copy-protected). However, complete excludability seems hard to achieve: simply specifying intellectual property laws does not ensure that they will be enforced; similarly, technical protective measures are often imperfect and can be "cracked". As a result, illicit copying (or piracy) cannot be completely avoided.

Over the last decade, the fast penetration of the Internet and the increased digitization of information have turned piracy of information goods (in particular music, movies and software) into a topic of intense debate. Not surprisingly, economists have recently shown a renewed interest in information goods piracy. The recent contributions (see the critical review of Peitz and Waelbroeck (2003) and the references therein) revive the literature on the economics of copying and copyright, which was initiated some twenty years ago (with the notable exception of Plant (1934); for a recent survey (and extension) of the early literature, see Watt, 2000). Generally, the literature on the economics of copying and copyright abstracts away the strategic interaction among producers of information goods. It is generally argued that the degree of horizontal differentiation

between information goods (like CDs or books) is so large that one can assume that the demand for any particular good is independent of the prices of other goods. An exception is Johnson (1985): his 'fixed cost model' considers a copying technology that involves an investment in costly equipment. As the author emphasizes, "[a]n interesting feature of this model is that the demand for any particular work is affected indirectly by the prices of other works since they affect a consumer's decision to invest in the copying technology". However, because the focus is mainly on the welfare implications of copying, Johnson (1985) does not fully explore the effects of the strategic interaction induced by 
the fixed cost of copying.

The aim of the present paper is to address more systematically the strategic interaction among producers of information goods, which is induced by the existence of increasing returns to scale in the copying technology. Like a number of recent papers, we use the framework proposed by Mussa and Rosen (1978) for modelling vertical (quality) differentiation: copies are seen as lower-quality alternatives to originals (i.e., if copies and originals were priced the same, all users would prefer originals). Information goods are assumed to be perfectly horizontally differentiated. This does not mean, however, that the demands for different goods can be treated as independent: as in Johnson (1985), demands are interdependent because the copying technology exhibits increasing returns to scale.

As a first step, we abstract away from strategic interaction and solve the case of a cartel selling all information goods as a bundle. In this case, the model boils down to the single-good problem analyzed in, e.g., Belleflamme (2002), Yoon (2002) or Bae and Choi (2003). The cartel faces two types of users with two different behaviors and demand functions: "loyal users" prefer not to use any good rather than copying them all; the opposite prevails for "copying users". Together, the two categories of users define a kinked demand curve for the cartel. Profit maximization over such demand yields three possible attitudes, which we can describe by using Bain (1956)'s taxonomy of an incumbent's behavior in the face of an entry threat. The cartel is either able to 'blockade' piracy, or the cartel must decide whether to 'deter' piracy (through limit-pricing) or to 'accommodate' it. We delineate regions of parameters where each of these three attitudes is observed. Intuitively, the cartel chooses to blockade, deter or accommodate piracy if the quality/price ratio of copies is, respectively, low, intermediate or high.

We turn next to an oligopoly setting where each information good is controlled by a single producer. Because of increasing returns to scale in copying, the demand for some original depends on the prices of all other originals. To make the analysis of the pricing game tractable, we focus on symmetric Bertrand-Nash equilibria (in pure strategies). Accordingly, we derive the demand for the original supplied by an individual firm under the assumption that all other originals are priced the same. The main source of complexity comes from the fact that, when we consider the demand for a single original (rather than for a bundle containing all originals), a third category of users appears. So-called "reversing users" change their attitude towards the other goods according to the use they make of the good supplied by the individual firm: if they do not purchase that good, they prefer to copy it along with the other goods; if they do purchase that good, they decide either to purchase the other goods or not to use them. The presence of reversing users significantly complicates the analysis. Demand functions may include many regimes because each firm 
can face three categories of users or some combination of these. Such demand peculiarities yield best response function with upward and downward sloping segments, upward and downward jumps.

Despite these complexities, we are able to present some general results about symmetric equilibria in the pricing game. First, we establish that oligopolists are able to blockade piracy over the same range of parameters as the cartel (basically when the quality/price ratio of copies is very low). Second, we show that deterrence of piracy cannot be a symmetric equilibrium when the quality of copies is sufficiently low (in the sense that users value $n$ copies less than $(n-1)$ originals). To get some intuition about this result, note that in that case, high valuation users are loyal users: the bad quality of copies refrain them to use the copying technology. The consumer basis of an individual firm consists thus of two types of users: firstly, loyal users who are willing to buy the original at any price above some limit price and, secondly, reversing users who are willing to change their decision to copy only if the individual firm sets some prices below the limit price. Therefore, to deter potential reversing users, each individual firm must set a price above the limit price. The candidate for a symmetric equilibrium in such case would be a price larger than the unconstrained monopoly price on loyal users. But then, each firm would have an incentive to free-ride on the other firms' deterrence effort and set the monopoly price. A third general result concerns accommodation of piracy. Intuitively, if all other firms set a high price and entice users to pirate, the best response for a single firm is to set a low price and accommodate piracy. It is therefore likely that firms do not set the same price, which means that accommodation of piracy cannot be a symmetric equilibrium. This is certainly true when the price of other originals is larger than some upward limit that we identify.

Although these results are important, they fall short of giving a full characterization of symmetric equilibria in the pricing game. To reach a full characterization, we examine two classes of examples where the number of kinks in the demand function is usefully reduced. First, we focus on the case where the number of varieties is sufficiently large so that the average cost of copying the last original is a constant. In that case, there exists no symmetric equilibrium as soon as copies are attractive enough so that piracy cannot be blockaded. The inexistence of symmetric equilibria stems from firms' free-riding behavior with respect to the threat of piracy. If all firms takes this threat seriously and quote low prices to accommodate users, then they put a price too low and there exists an opportunity for a single firm to raise its price while keeping a sufficiently large demand and making a larger profit. The latter result is driven by the presence of a significant number of users with very low value for originals and copies. In the second class of examples, we focus instead on users with a sufficiently high valuation for originals and copies. Now, more equilibria may exist. In particular, it is possible to find situations where the common price set 
by all firms deters or accommodates piracy.

Finally, we draw some insights by comparing cartels and oligopolies. In oligopolies, individual firms are able to free ride on each other by extracting some additional copiers' or buyers' surplus which cannot be appropriated through the single price of the cartel. This leads to several implications. First, in contrast to cartels, there often exists no equilibrium with a symmetric (single) price in oligopolies. Second, symmetric prices in oligopolies (if they exist) can exceed the cartels' price. For instance, when users have high valuations for originals and copies, the equilibrium price that accommodates piracy is larger for oligopolies than for cartels.

The rest of the paper is organized as follows. In Section 2, we lay out the model. In Section 3, we analyse the case of a cartel selling the information goods as a bundle. Next, we turn to the oligopoly case. First, we determine the demand for a single original in Section 4. Second, we derive best responses and general results about symmetric equilibria in Section 5. Third, to get more specific results, we examine two particular cases in Section 6: we assume either that there are many varieties or we focus on high valuation users; we also provide some elements of comparison with the cartel case. Finally, we conclude in Section 7.

\section{Users}

There is a continuum of potential users who can consume from a set $N$ of information goods (with $|N| \equiv n \geq 2$ ). These information goods are assumed to be perfectly (horizontally) differentiated and equally valued by the users. In particular, users are characterized by their valuation, $\theta$, for any information good. We assume that $\theta$ is uniformly distributed on the interval $[\underline{\theta}, \bar{\theta}]$.

Each information good $i \in N$ is imperfectly protected and thus "piratable". As a result, users can obtain each information good in two different ways: they can either buy the legitimate product (an "original") or acquire a copy of the product. It is reasonable to assume that all users see the copy as a lowerquality alternative to the original. ${ }^{1}$ Therefore, in the spirit of Mussa and Rosen (1978), we posit some vertical (quality) differentiation between the two variants of any information good: letting $s_{o}$ and $s_{c}$ denote, respectively, the quality of an original and a copy, we assume that $0<s_{c}<s_{o}{ }^{2}$

As for the relative cost of originals and copies, we let $p_{i}$ denote the price of

\footnotetext{
${ }^{1}$ This assumption is common (see, e.g., Gayer and Shy, 2003) and may be justified in several ways. In the case of analog reproduction, copies represent poor substitutes to originals and are rather costly to distribute. Although this is no longer true for digital reproduction, originals might still provide users with a higher level of services, insofar as that they are bundled with valuable complementary products which can hardly be obtained otherwise.

${ }^{2}$ Similar models are used by Koboldt (1995) to consider commercial copying and by Yoon (2002) and Bae and Choi (2003) to analyze the market for a single information good.
} 
original $i$ and we assume that users have access to a copying technology with the following properties. Letting $C(y)$ denote the total cost of $y$ illicit copies (and $A C(y)=C(y) / y$ denote the average cost), we assume

Assumption $1 C(y)>C(y-1)$ and $A C(y) \leq A C(y-1)$,

Assumption $2 A C(n)<\bar{\theta} s_{c}<A C(1)$.

According to Assumption 1, the copying cost function is increasing and exhibits (weakly) increasing returns to scale in copying. ${ }^{3}$ The assumption for continuous number of copies would be $C^{\prime}(y)>0 \geq C^{\prime \prime}(y)$. In the sequel we will use the notation $C^{\prime}(y)$ to denote $C(y)-C(y-1)$. Assumption 2 simply says that no user will invest in the copying technology if it is to copy only one original $\left(\theta s_{c}<C(1) \forall \theta\right)$, but that some users might invest if it is to copy all $n$ originals $\left(\exists \theta\right.$ s.t. $\left.\theta n s_{c}>C(n)\right)$. The combination of Assumptions 1 and 2 implies that constant returns to scale may apply only for a limited range of copies: the copying technology exhibits strict increasing returns to scale anywhere else.

Putting these elements together (and normalizing to zero the utility from not consuming a particular information good), we can express the user's utility function. If a user indexed by $\theta$ purchases a subset $X \subseteq N$ (with $0 \leq|X| \equiv$ $x \leq n$ ) of originals and acquires a number $y$ of copies (with $0 \leq y \leq n-x$ ), her net utility is given by

$$
U_{\theta}(x, y)=\theta\left(x s_{o}+y s_{c}\right)-\sum_{i \in X} p_{i}-C(y) .
$$

By the properties of $C(y)$, the utility function is strictly convex in $y$. Moreover, if a subset of the original goods are sold at the same price, the utility function is also strictly convex in the number of goods purchased. In such a situation, all goods in the subset are symmetric (same price, same quality of originals and copies) and it follows that the most profitable option for the users is always to make the same use of all these goods. We demonstrate this result in the next lemma.

Lemma 1 Consider a subset $S \subseteq N$ (with $0<|S| \equiv s \leq n$ ). Suppose $p_{j}=p$ $\forall j \in S$. Then any user maximizes her utility over the goods in $S$ by either purchasing, copying, or not using them all.

Proof. Let $x$ (resp. $y$ ) denote the number of goods in subset $S$ that user $\theta$ chooses to purchase (resp. copy), with $0 \leq x+y \leq s$. Let $y^{\prime}$ denote the number

\footnotetext{
${ }^{3}$ The magnitude of these increasing returns to scale will depend on the precise nature of copying: returns will be quite low if copies are acquired piecemeal on a parallel market from some large-scale pirate; returns will be much larger if copies are directly produced by the consumer himself (for instance, by burning CDs using a CD-RW drive).
} 
of goods in the complementary subset $S^{\prime}=N \backslash S$ that user $\theta$ chooses to copy. The user's utility on the goods in subset $S$ can then be rewritten as

$$
U_{\theta}^{S}(x, y)=x\left(\theta s_{o}-p\right)+y \theta s_{c}-C\left(y+y^{\prime}\right) .
$$

For any $y^{\prime}$, this expression is convex in $x$ and $y$. Hence, the maximum can only be reached at corner solutions: $x=y=0, x=s$, or $y=s$.

The previous result proves useful to derive the demand function for some specific original $i \in N$ from expression (1). We consider two cases in turn. First, as a benchmark, we suppose that the $n$ producers of originals act as a cartel and choose a unique price for all originals. Next, we turn to an oligopoly setting and solve the pricing game for its symmetric equilibria.

\section{Cartel}

This section presents the benchmark case of a cartel setting a single price for all supplied varieties. The cartel indeed offers an interesting point of comparison since, in this case, the model boils down to the single-good problem analyzed in, e.g., Belleflamme (2002), Yoon (2002) or Bae and Choi (2003). In addition, it is realistic to assume that, in order to preserve the cartel's stability, producers restrain themselves to set the same price for all originals. ${ }^{4}$

Suppose that the $n$ producers of originals form a cartel. The cartel's objective is to maximize joint profits by choosing the price $p$ at which originals are sold. From Lemma 1, we know that users will treat all goods alike and, depending on $p$, will decide either to purchase all goods, or to copy them all, or not to use any. Therefore, user $\theta$ will purchase all originals if and only if

$$
U_{\theta}(n, 0) \geq \max \left\{U_{\theta}(0, n), U_{\theta}(0,0)\right\},
$$

where $U_{\theta}(n, 0)=n\left(\theta s_{o}-p\right), U_{\theta}(0, n)=n \theta s_{c}-C(n)$, and $U_{\theta}(0,0)=0$. Developing the latter condition, one observes that the cartel faces two types of users with two different behaviors and demand functions.

"Loyal users". Users for whom $U_{\theta}(0,0) \geq U_{\theta}(0, n) \Longleftrightarrow \theta \leq A C(n) / s_{c}$ prefer not to use any good rather than copying them all. The cartel considers thus these users as "loyal", as it faces no threat of copying from them. Condition (2) rewrites for loyal users as $n\left(\theta s_{o}-p\right) \geq 0$. The 'marginal loyal user', who is identified by $\theta^{\ell}(p)=p / s_{o}$, is indifferent between purchasing all originals and not using any good. Inverting the previous relation, we define the inverse demand for loyal users as the following price function:

$$
p^{\ell}(\theta)=\theta s_{o}
$$

\footnotetext{
${ }^{4}$ Note that the cartel differs from the multiproduct monopolist in the sense that the cartel is not allowed to use price discrimination. A complete analysis of the multiproduct monopolist's profit-maximizing price schedule is beyond the scope of this paper.
} 
"Copying users". On the other hand, users for whom $U_{\theta}(0, n) \geq U_{\theta}(0,0)$ prefer to copy all goods rather than not using them. For these "copying" users, condition (2) rewrites as $n\left(\theta s_{o}-p\right) \geq n \theta s_{c}-C(n)$. The "marginal copying user', identified by

$$
\theta^{c}(p)=\frac{p-A C(n)}{s_{o}-s_{c}},
$$

is indifferent between purchasing and copying all goods. The corresponding inverse demand is given by

$$
p^{c}(\theta)=\theta\left(s_{o}-s_{c}\right)+A C(n)
$$

In sum, the price function facing the cartel can simply be written as

$$
p(\theta)=\min \left\{p^{\ell}(\theta), p^{c}(\theta)\right\}= \begin{cases}p^{\ell}(\theta) & \text { if } \theta \leq A C(n) / s_{c} \\ p^{c}(\theta) & \text { otherwise }\end{cases}
$$

This price function yields the type of the marginal buyer when he/she is a loyal or a copying user. It is piece-wise linear and weakly concave in $\theta$. The slope of the linear pieces are such that $(d / d \theta) p^{c}(\theta)<(d / d \theta) p^{\ell}(\theta)$.

Targeting loyal users or accommodating copying users? Let $\theta_{\ell c}=$ $A C(n) / s_{c}$ denote the user who separates loyal and copying users. We have that $p^{\ell}\left(\theta_{\ell c}\right)=p^{c}\left(\theta_{\ell c}\right)=\left(s_{o} / s_{c}\right) A C(n) \equiv \bar{p}$. We call $\bar{p}$ the copying deterrence price: for $p \leq \bar{p}$, the cartel impedes copying users to copy and faces only loyal users. ${ }^{5}$ We can thus write the embedded maximization problem the cartel must solve in the following way:

$$
\max _{\pi}\left\{\begin{array}{ll}
\max _{p} \pi^{\ell}(p)=\left(\bar{\theta}-\theta^{\ell}(p)\right) p /(\bar{\theta}-\underline{\theta}) & \text { s.t. } p \leq \bar{p} ; \\
\max _{p} \pi^{c}(p)=\left(\bar{\theta}-\theta^{c}(p)\right) p /(\bar{\theta}-\underline{\theta}) & \text { s.t. } p \geq \bar{p} .
\end{array}\right\} .
$$

By analogy with Bain (1956)'s taxonomy of an incumbent's behavior in the face of an entry threat, we will say that the cartel is either able to 'blockade' copying, or that it must decide whether to 'deter' copying or 'accommodate' it. Let us now define and compare these three options. Suppose first that the cartel targets loyal users. The unconstrained profit-maximizing price and profit per good are easily computed as

$$
p^{\ell *}=\frac{s_{o}}{2} \bar{\theta}, \pi^{\ell *}=\frac{s_{o}}{4(\bar{\theta}-\underline{\theta})} \bar{\theta}^{2} .
$$

This solution meets the constraint if and only if $p^{\ell *} \leq \bar{p} \Longleftrightarrow A C(n) \geq\left(s_{c} / 2\right) \bar{\theta}$. In this case, we can say that copying is actually blockaded: the cartel safely sets

\footnotetext{
${ }^{5}$ This price corresponds to the usual limit price discussed in piracy models with a single good (see, e.g., Bae and Choi, 2003).
} 
its price as if copying was not a threat. Otherwise, copying cannot be blockaded but the cartel modifies its behavior to successfully deter copying: it will choose the highest price compatible with the constraints, i.e.,

$$
p^{C}=\left(s_{o} / s_{c}\right) A C(n), \text { which implies } \pi^{C}=\frac{s_{o}\left(\bar{\theta} s_{c}-A C(n)\right) A C(n)}{s_{c}^{2}(\bar{\theta}-\underline{\theta}) .} .
$$

The other option is to set a higher price and accommodate copying users. Here, the unconstrained profit-maximizing price is equal to

$$
p^{c *}=\frac{1}{2}\left(\left(s_{o}-s_{c}\right) \bar{\theta}+A C(n)\right), \text { which implies } \pi^{c *}=\frac{\left(\left(s_{o}-s_{c}\right) \bar{\theta}+A C(n)\right)^{2}}{4\left(s_{o}-s_{c}\right)(\bar{\theta}-\underline{\theta})} .
$$

This solution satisfies the constraints if and only if

$$
p^{c *} \geq \bar{p} \Longleftrightarrow A C(n) \leq \frac{s_{c}\left(s_{o}-s_{c}\right)}{2 s_{o}-s_{c}} \bar{\theta}
$$

If the latter condition is not met, it is easily checked that the corner solution is equivalent to copying deterrence.

Comparing the profit levels $\pi^{\ell *}, \pi^{C}$, and $\pi^{c *}$, we conclude that the cartel's optimal strategy depends on the relative attractiveness of copies (i.e., for a given value of $s_{o}$, on the values of $A C(n)$ and $s_{c}$ ), as summarized in the following proposition.

Proposition 1 The cartel's profit-maximization price is

$$
p^{*}=\mid \begin{array}{lll}
p^{\ell *}=\frac{s_{o}}{2} \bar{\theta} & \text { for } \frac{s_{c}}{2} \bar{\theta} \leq A C(n) \leq s_{c} \bar{\theta} & \text { (blockade), } \\
p^{C}=\frac{A C(n) s_{o}}{s_{c}} & \text { for } \frac{s_{c}\left(s_{o}-s_{c}\right)}{2 s_{o}-s_{c}} \bar{\theta} \leq A C(n) \leq \frac{s_{c}}{2} \bar{\theta} & \text { (deter), } \\
p^{c *}=\frac{\left(s_{o}-s_{c}\right) \bar{\theta}+A C(n)}{2} & \text { for } 0 \leq A C(n) \leq \frac{s_{c}\left(s_{o}-s_{c}\right)}{2 s_{o}-s_{c}} \bar{\theta} & \text { (accommodate). }
\end{array}
$$

We now turn to the oligopoly setting.

\section{Demands for originals in oligopolies}

We use expression (1) to derive the demand function for some specific original $i \in N$. As will soon become apparent, the demand for original $i$ depends, in a rather complicated way, on the relative quality of originals and copies $\left(s_{o}\right.$ and $s_{c}$ ), on the cost of copying, on the price of good $i$ and, because of increasing returns to scale in copying, on the prices of all other originals. To make the analysis of the pricing game tractable, we focus on symmetric Bertrand-Nash equilibria (in pure strategies). Accordingly, we derive the demand for original $i$ under the assumption that all other originals are priced the same: $p_{j}=p$ $\forall j \neq i$. 
We first define the condition under which a typical user $\theta$ is better off purchasing good $i$ (and choosing whichever use is the most profitable for the other goods) than copying or not using good $i$ (and still choosing whichever use is the most profitable for the other goods). From Lemma 1, we know that the most profitable option is always to make the same use of all other goods. Using this result, we can express the condition for user $\theta$ to buy an original of information good $i$. To ease the exposition, we introduce the following notation. Let

$$
B_{\theta}^{-i}(p) \equiv(n-1)\left(\theta s_{o}-p\right) \quad \text { and } \quad P_{\theta}(y) \equiv y\left(\theta s_{c}-A C(y)\right)
$$

respectively be user $\theta$ 's utility from buying all goods but good $i$ at price $p$ and user $\theta$ 's utility from "pirating" $y$ goods. Then, we have the following result:

Lemma 2 Facing a price vector $\left(p_{i},\left(p_{j}=p\right)_{j \neq i}\right)$, a user of type $\theta$ purchases original $i$ if and only if

$$
\theta s_{o}-p_{i}+\max \left\{B_{\theta}^{-i}(p), 0, P_{\theta}(n-1)\right\} \geq \max \left\{B_{\theta}^{-i}(p), 0, P_{\theta}(n)\right\} .
$$

Proof. The left-hand side of the inequality follows directly from Lemma 1. To derive the right-hand side, we express, in Table 1, the highest net utility user $\theta$ can obtain from all $n$ goods if she does not purchase good $i$. Assumption 2 $\left(P_{\theta}(1)<0\right)$ rules out the top left and top right options as candidate maximum. So does Assumption 1 for the bottom middle option. (For this option to be maximum, we would need $P_{\theta}(n-1)>P_{\theta}(n) \Longleftrightarrow C(n)-C(n-1)>\theta s_{c}$ and $P_{\theta}(n-1)>0 \Longleftrightarrow \theta s_{c}>A C(n-1)$. But, as $A C(n)<A C(n-1)$, the two inequalities are clearly incompatible.) We are thus left with the three options appearing in the right-hand side of inequality (3).

\begin{tabular}{|c|c|c|c|}
\hline \multirow{2}{*}{ Good $i$} & \multicolumn{3}{|c|}{ Other $n-1$ goods } \\
\cline { 2 - 4 } & Purchased & Copied & Not used \\
\hline Copied & $P_{\theta}(1)+B_{\theta}^{-i}(p)$ & $P_{\theta}(n)$ & $P_{\theta}(1)$ \\
\hline Not used & $B_{\theta}^{-i}(p)$ & $P_{\theta}(n-1)$ & 0 \\
\hline
\end{tabular}

Table 1: Net utility when good i is not purchased

To derive the demand schedule for some original $i$, we need to express the exact form of the purchasing decision (3) according to how the price of the other originals compares with the value of the parameters. To clarify the exposition, we analyze the case where $P_{\theta}(n) \geq P_{\theta}(n-1) \Longleftrightarrow \theta \geq C^{\prime}(n) / s_{c}$ (we show in a footnote that the other case is very simple). Developing expression (3), one observes that firm $i$ potentially faces users with three different behaviors and demand functions: on top of the loyal and copying users identified in the cartel case, there is a new category of so-called "reversing" users. Let us identify these three categories. 
"Loyal users". Users for whom $\max \left\{B_{\theta}^{-i}(p), 0\right\} \geq P_{\theta}(n)$ are such that, whatever use they make of good $i$, they always prefer to purchase the $(n-1)$ other goods and never find it profitable to invest in the copying technology. Therefore, firm $i$ considers these users as loyal, as it faces no threat of copying from them. Condition (3) rewrites for loyal users as $\theta s_{o}-p_{i} \geq 0$. The 'marginal loyal user', who is identified by $\theta_{\ell}\left(p_{i}\right)=p_{i} / s_{o}$, is indifferent between purchasing original $i$ and not using good $i$; in any case, he/she purchases the $n-1$ other originals. ${ }^{6}$ Inverting the previous relation, we define the inverse demand for loyal users as the following price function:

$$
p_{i}^{\ell}(\theta)=\theta s_{o}
$$

"Copying users". At the other extreme, users for whom $\max \left\{B_{\theta}^{-i}(p), 0\right\} \leq$ $P_{\theta}(n-1)$ prefer to copy the $(n-1)$ other goods whatever their decision about good $i$. This is so because the price $p$ of the other originals is sufficiently high for them. For these users, Condition (3) rewrites as $\theta s_{o}-p_{i}+P_{\theta}(n-1) \geq P_{\theta}(n)$; firm $i$ 's price is not going to change the users' decision of investing in the copying technology. The 'marginal copying user', identified by

$$
\theta_{c}\left(p_{i}\right)=\frac{p_{i}-C^{\prime}(n)}{s_{o}-s_{c}},
$$

is indifferent between purchasing original $i$ (and copying all other goods) and copying all $n$ goods. The corresponding inverse demand is given by

$$
p_{i}^{c}(\theta)=\theta s_{o}-\left(P_{\theta}(n)-P_{\theta}(n-1)\right)=C^{\prime}(n)+\theta\left(s_{o}-s_{c}\right) .
$$

Note that, as $C^{\prime}(n) \leq A C(n)$, the inverse demand of copying users is lower in the oligopoly case than in the cartel case. In the present case, users consider only original $i$, whereas in the cartel case, they consider the bundle of all originals.

"Reversing users". In contrast with the two previous groups, users for whom $P_{\theta}(n) \geq \max \left\{B_{\theta}^{-i}(p), 0\right\} \geq P_{\theta}(n-1)$ change their attitude towards the $(n-1)$ other goods according to the use they make of good $i$. If they do not purchase good $i$, they prefer to copy it along with the other goods. If they do purchase good $i$, they decide either to purchase the other goods or not to use them, according to whether $B_{\theta}^{-i}(p)$ is larger or lower than zero. More precisely, we distinguish between two groups of "reversing users".

\footnotetext{
${ }^{6}$ If $\theta<C^{\prime}(n) / s_{c}$, we have users for whom $P_{\theta}(n-1)>P_{\theta}(n)$. It is straightforward to show that these users are loyal. We can indeed check that $\max \left\{B_{\theta}^{-i}(p), 0\right\} \geq P_{\theta}(n-1)$. Suppose first that $p / s_{o} \leq \theta \leq C^{\prime}(n) / s_{c}$. Then $B_{\theta}^{-i}(p) \geq P_{\theta}(n-1) \Longleftrightarrow \theta \geq[p-A C(n-1)] /\left(s_{o}-s_{c}\right)$. But $p / s_{o} \geq[p-A C(n-1)] /\left(s_{o}-s_{c}\right) \Longleftrightarrow p / s_{o} \leq A C(n-1) / s_{c}$, which is the case as $C^{\prime}(n)<A C(n-1)$. Suppose next that $\theta<p / s_{o} \leq C^{\prime}(n) / s_{c}$. Then $0 \geq P_{\theta}(n-1) \Longleftrightarrow \theta \leq$ $A C(n-1) / s_{c}$, which is again the case as $C^{\prime}(n)<A C(n-1)$.
} 
- We call " $\alpha$-reversing users" those users for whom $B_{\theta}^{-i}(p) \geq 0$ (i.e., if $\left.\theta \geq p / s_{o}\right)$. Condition (3) rewrites for these users as $\theta s_{o}-p_{i}+B_{\theta}^{-i}(p) \geq$ $P_{\theta}(n)$. By setting too high a price, firm $i$ may trigger users to reverse their decision of purchasing $n-1$ items to copying all items. The marginal user is identified by

$$
\theta_{\alpha}\left(p_{i}, p\right)=\frac{p_{i}+(n-1) p-C(n)}{n\left(s_{o}-s_{c}\right)}
$$

this user is indifferent between purchasing and copying all $n$ originals. The corresponding inverse demand is given by

$$
p_{i}^{\alpha}(p, \theta)=\theta s_{o}-\left(P_{\theta}(n)-B_{\theta}^{-i}(p)\right)=C(n)-(n-1) p+\theta n\left(s_{o}-s_{c}\right) .
$$

- The " $\beta$-reversing users" are such that $B_{\theta}^{-i}(p) \leq 0$ (i.e., if $\theta \leq p / s_{o}$ ). The difference is that if these users purchase original $i$, they do not consume the $n-1$ other goods. Here, condition (3) rewrites as $\theta s_{o}-p_{i} \geq P_{\theta}(n)$. The marginal user is identified by

$$
\theta_{\beta}\left(p_{i}, p\right)=\frac{C(n)-p_{i}}{n s_{c}-s_{o}} .
$$

The corresponding inverse demand is given by

$$
p_{i}^{\beta}(\theta)=\theta s_{o}-P_{\theta}(n)=C(n)-\theta\left(n s_{c}-s_{o}\right) .
$$

In summary, the inverse demand for reversing users is given by $p_{i}^{r}(p, \theta)=$ $\max \left\{p_{i}^{\alpha}(\theta, p), p_{i}^{\beta}(\theta)\right\}$.

Synthesis. The above analysis shows that users choose between loyal consumption and three strategies of piracy: copy all, reverse to copying from buying $(n-1)$ originals or from buying no original. The maximum price that each user with type $\theta$ is willing to pay for original $i$ is obviously the minimum of the value of an original and the value of the best piracy strategy. That is,

$$
p_{i}(\theta)=\min \left\{p_{i}^{\ell}(\theta), \max \left[p_{i}^{c}(\theta), p_{i}^{\alpha}(\theta, p), p_{i}^{\beta}(\theta)\right]\right\} .
$$

This 'price function' maps the user's type $\theta$ with his largest willingness to pay for the original $i$ given the piracy alternatives. Function (4) is far from trivial for three reasons: first, two cases have to be distinguished according to the relative quality of copies, as can be seen in Figures 1 and 2; second, the price function can include kinks that depend on the price of the other goods; third, more than one type of users may purchase the original at some ranges of prices $p_{i}$. The demand function for good $i$ is obtained from this price function by aggregating all types of purchasing users at each price $p_{i}$. Naturally, the demand function suffers from the same complexities as the price function. In particular, we show below that it includes concave and convex kinks. 


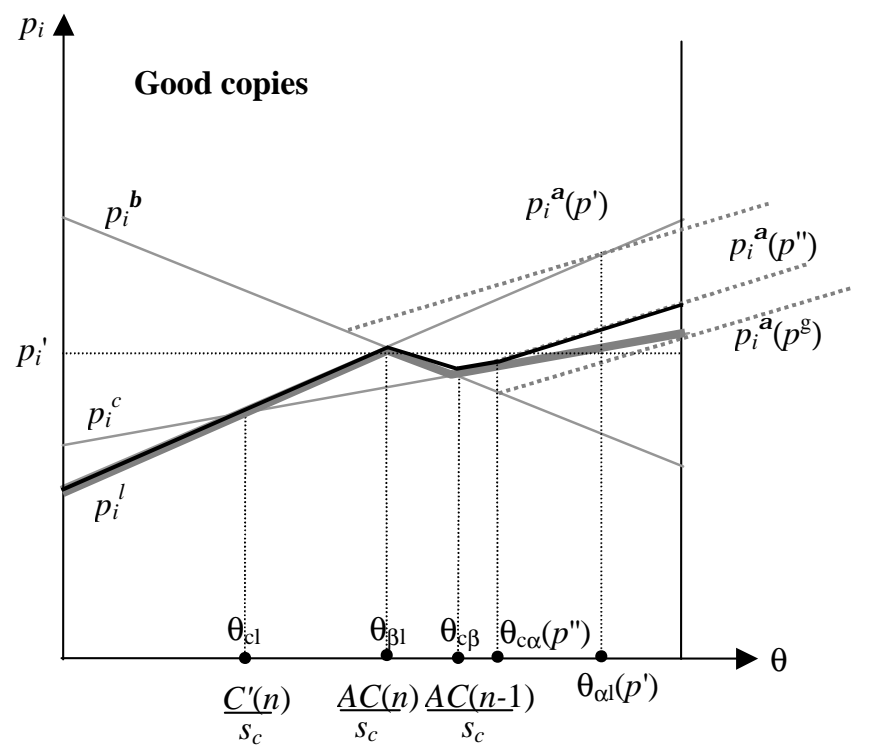

Figure 1: Price function for good copies

As the properties of the price function and its kinks are at the core of the oligopoly analysis, we now pay closer attention to the three sources of complexity. Let us first compare the four functions composing $p_{i}(\theta)$. We observe the following: (i) $p_{i}^{\ell}(\theta), p_{i}^{c}(\theta), p_{i}^{\alpha}(p, \theta)$ are increasing functions of $\theta$, while $p_{i}^{\beta}(\theta)$ is a decreasing function of $\theta$ (assuming that $n$ copies provide users with a larger gross utility than a single original: $n s_{c}>s_{o}$ ); (ii) $p_{i}^{\alpha}(p, \theta)$ shifts downward as $p$ increases, while the other functions are independent of $p$.

Let us now examine where these functions intersect. We define the cutoff type $\theta_{k m}$ as the user type for whom the schedule $p_{i}^{k}(\theta, p)$ intersects with $p_{i}^{m}(\theta, p)$, with $k, m \in\{\ell, c, \alpha, \beta\}$. From Figures 1 and 2 , it can be seen that the price function $p_{i}(\theta)$ corresponds to the inverse demand function of loyal users with a 'slice cut', which might appear for types above $\theta_{\beta \ell} \equiv A C(n) / s_{c}$, and which spreads to the right as $p$ increases (larger prices of the other goods make the copying technology more attractive and thereby, constrain further firm $i$ 's pricing possibilities). There can exist up to four kinks in the price function $p_{i}(\theta)$ : on the one hand, the schedule $\max \left\{p_{i}^{c}, p_{i}^{\alpha}, p_{i}^{\beta}\right\}$ generates at most two kinks at some combinations of types $\theta_{\alpha c}, \theta_{c \beta}$ or $\theta_{\alpha \beta}$; on the other hand, the intersection of the latter schedule with the schedule $p_{i}^{\ell}$ can also generate two kinks at types $\theta_{\beta \ell}$ and $\theta_{\alpha \ell}$.

As we are ultimately interested in firm $i$ 's reaction to the price of the other goods, we need to understand the impact of $p$ on the price function. First, it is easily shown that no more than two kinks will vary with the price of other goods $p$ : these kinks are located at types $\theta_{\alpha \ell}$ and either $\theta_{\alpha c}$ or $\theta_{\alpha \beta}$. Second, one readily checks that $p_{i}^{\alpha}(p, \theta)$ increases in $\theta$ more steeply than $p_{i}^{\ell}(\theta)$ if and 


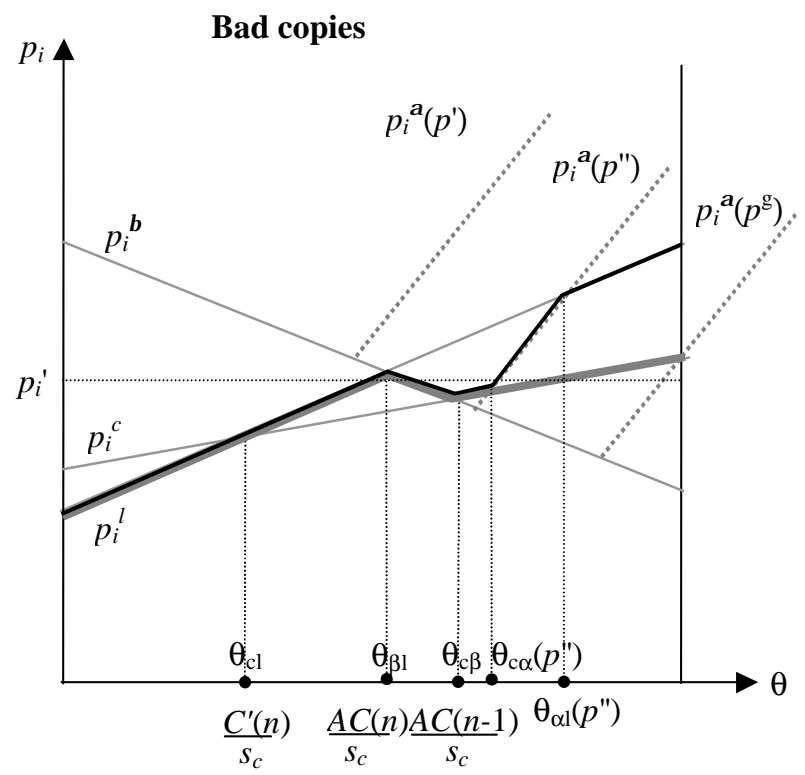

Figure 2: Price function for bad copies

only if $(n-1) s_{o}>n s_{c}$. Thus, firm $i$ 's behavior is likely to differ according to the state of the condition $(n-1) s_{o}>n s_{c}$. We make the following definition.

Definition 4.1 The copy technology delivers 'good' copies if $n s_{c}>(n-1) s_{o}$ and 'bad' copies if $n s_{c} \leq(n-1) s_{o}$.

We talk of 'good copies' when $n$ copies provide users with more gross utility than $n-1$ originals. Another way to put it is to say that all users loose less, in terms of gross utility, when they consume copies instead of originals for all goods $\left(n\left(s_{o}-s_{c}\right)\right)$ than when they refrain from consuming a single original $\left(s_{o}\right)$. The distinction between good and bad copies is crucial when it comes to separate loyal and $\alpha$-reversing users. In the case of good copies, high valuation users (with $\theta>\theta_{\alpha \ell}(p)$ ) are $\alpha$-reversing users: as $n$ copies provide all users with more utility than $(n-1)$ originals, users with higher valuations are more likely to reverse to copying all items. One also observes that $\theta_{\alpha \ell}(p)$ is a decreasing function of $p$. In the case of bad copies, we have the opposite situation: high valuation users are loyal users. The bad quality of copies refrain the latter to use the copying technology. Obviously, $\theta_{\alpha \ell}(p)$ is an increasing function of $p$.

Finally, we observe that more than one type of users may purchase the original at some ranges of prices $p_{i}$. For instance, when the price is equal to $p_{i}^{\prime} \in\left(p_{i}^{\beta}\left(\theta_{\beta \ell}\right), p_{i}^{\beta}\left(\theta_{c \beta}\right)\right)=\left(p_{i}^{\beta}\left(A C(n-1) / s_{c}\right), p_{i}^{\beta}\left(A C(n) / s_{c}\right)\right)$, the users who are willing to purchase original $i$ can be either loyal users (e.g. at $p_{i}^{\ell}=p_{i}^{\prime}$ ), $\alpha$-reversing users (e.g. at $p_{i}^{\alpha}=p_{i}^{\prime}$ ) and $\beta$-reversing users (e.g. at $p_{i}^{\beta}=p_{i}^{\prime}$ ). The analysis of this particular section of the demand function is rather complicated 
and of limited interest in terms of economic insight. In the sequel, we shall impose some assumptions to rule out the existence of more than one type of users in the demand function.

Collecting the previous results, we can provide information about the nature of some kinks in the price function $p_{i}$, more precisely about the local convexity of the kinks.

Lemma 3 Whether copies are good or bad, the price function is (increasing and) concave in $\theta$ in the neighborhood of $\theta_{\alpha \ell}(p)$ and, (increasing and) convex in the neighborhood of $\theta_{\alpha c}(p)$.

These properties can readily be checked in Figures 1 and 2 when the price of the other goods is equal to $p^{\prime}$ or $p^{\prime \prime}$. As a consequence, we anticipate that best response functions will be continuous when shifting from regime $(\ell)$ to $(\alpha)$, but discontinuous when shifting from regime $(\alpha)$ to $(c)$. The next section examines this issue in detail.

\section{Best responses and symmetric equilibria}

In this section we determine firm $i$ 's best-response function when all other originals are sold at the same price. Then, we characterize the symmetric Bertrand-Nash equilibria (in pure strategies) by looking for the fixed points of the best-response function. As we have just shown, demand functions include many regimes because each firm can face loyal users, full copying users, reversing users or some combination of these. Such demand peculiarities may yield best response function with upward and downward sloping segments, upward and downward jumps. Before proposing several assumptions to alleviate the complexity, we present some general results.

\subsection{Attitude towards $\alpha$-reversing users}

First, when other originals are sufficiently cheap, piracy of good $i$ can naturally be blockaded. For bad copies, when the price of the other goods $p$ is below $p_{i}^{\ell}\left(\theta_{\beta \ell}\right)=A C(n) s_{o} / s_{c}$, copying attracts no user: all users are loyal. In other words, there is no 'slice cut' in the price function displayed in Figure 2. Firm $i$ 's best response is the monopoly price on the demand of loyal users:

$$
R_{i}^{*}(p)=p_{i}^{\ell *} \equiv s_{o} \bar{\theta} / 2
$$

and the marginal buyer is equal to $\theta_{\ell}^{*}=\bar{\theta} / 2$. For a price of the other originals larger than or equal to $A C(n) s_{o} / s_{c}$, an increase in the price of good $i$ may entice some users to reverse from buying the $(n-1)$ other goods to copy all goods. That is, the firm may face $\alpha$-reversing users. In particular, when the price $p$ of other originals is sufficiently large, the marginal loyal buyer $\left(\theta_{i}^{\ell *} \equiv \bar{\theta} / 2\right)$ 
also becomes an $\alpha$-reversing user and firm $i$ can no longer apply the price $p_{i}^{\ell *}$. It is forced to revise its pricing decision along the price function $p_{i}(\theta)=$ $\min \left\{p_{i}^{\ell}(\theta), p_{i}^{\alpha}(p, \theta)\right\}$.

In this context, the user with type $\theta_{\alpha \ell}(p)$ is a pivotal user. The maximal price firm $i$ can charge to this user is equal to $p_{i}^{D}(p)=p_{i}^{\ell}\left(\theta_{\alpha \ell}(p)\right)$, i.e.,

$$
p_{i}^{D}(p)=\frac{(n-1) p-C(n)}{(n-1) s_{o}-n s_{c}} s_{o} .
$$

The function $p_{i}^{D}(p)$ gives, for a given price $p$ of the other originals, the price of original $i$ that deters loyal users from becoming $\alpha$-reversing users. The interpretation of this so-called ' $\alpha$-reversing user deterrence price' changes as we consider good or bad copies.

- In the case of good copies $\left(n s_{c}>(n-1) s_{o}\right)$, firm $i$ 's consumer basis consists of reversing users at any price $p_{i} \geq p_{i}^{D}(p)$ and of loyal users at smaller prices. Moreover, the limit-price $p_{i}^{D}(p)$ decreases with $p$ : as the other originals become more expensive, reversing becomes more interesting and users with the low valuations are enticed to reverse to copying. To keep these users, firm $i$ decreases its price.

- Conversely, with bad copies $\left(n s_{c}<(n-1) s_{o}\right)$, firm $i$ 's consumer basis consists of loyal users at any price $p_{i} \geq p_{i}^{D}(p)$ and of reversing users at smaller prices. To deter potential reversing users, firm $i$ must now set a high enough price, $p_{i} \geq p_{i}^{D}(p)$. Here, the limit-price increases with $p$. As the other originals become more expensive, the loyal users with the lowest valuations becomes reversing users; because the demand of these reversing users is rather inelastic, firm $i$ is willing to apply a higher price.

Given that demand functions are concave in $\theta$ around $\theta_{\alpha \ell}$ (see Lemma 3), firm $i$ continuously moves, according to the value of $p$, between the three following situations. First, if the the price $p$ of the other goods is large enough, users never use the copying technology and firm $i$ 's price and marginal user are given by $p_{i}^{\ell *} \equiv(\bar{\theta} / 2) s_{o}$ and $\theta_{\ell}^{*} \equiv \bar{\theta} / 2$. Whether copies are good or bad, it turns out that this solution is feasible as long as

$$
p \leq p^{f} \equiv \frac{C(n)}{n-1}+\frac{(n-1) s_{o}-n s_{c}}{2(n-1)} \bar{\theta},
$$

where $p^{f}$ is the price of competitors for which the $\alpha$-reversing user deterrence price is equal to the optimal price charged to loyal users; that is $p_{i}^{D}\left(p^{f}\right)=p_{i}^{\ell *}$. Note that when $A C(n) / s_{c}<\bar{\theta} / 2, p^{f} \geq A C(n) s_{o} / s_{c}$ if copies are bad and $p^{f}<A C(n) s_{o} / s_{c}$ if they are good. Thus, blockading stops to be a best response at higher prices $p$ of other originals under bad copying technologies than under good copying ones. By analogy with Bain's taxonomy, market conditions are 
such that potential entry (i.e., piracy) exerts no threat, so that incumbents (i.e., producers of originals) do not need to modify their behavior and continue to act as (local) monopolists.

Second, when the price $p$ of other goods is sufficiently low, firm $i$ faces only reversing users. Its optimal price and marginal user are now equal to

$$
\begin{aligned}
p_{i}^{\alpha *}(p) & =\frac{1}{2}\left(\bar{\theta} n\left(s_{o}-s_{c}\right)+C(n)-(n-1) p\right) \\
\theta_{\alpha}^{*}(p) & =\frac{\bar{\theta}}{2}-\frac{C(n)-(n-1) p}{2 n\left(s_{o}-s_{c}\right)} .
\end{aligned}
$$

This solution is feasible provided that (whether copies are good or bad)

$$
p \geq p^{d} \equiv \frac{C(n)}{n-1}+\frac{n\left(s_{o}-s_{c}\right)\left((n-1) s_{o}-n s_{c}\right)}{(n-1)\left((n+1) s_{o}-n s_{c}\right)} \bar{\theta}
$$

where $p^{d}$ is the price of competitors for which the reversing user deterrence price is equal to the optimal price charged to reversing users; that is, $p_{i}^{D}\left(p^{d}\right)=$ $p_{i}^{\alpha *}\left(p^{d}\right)$. It is readily checked that $p^{d}>p^{f}$.

Finally, when $p$ takes intermediate values (i.e., between $p^{f}$ and $p^{d}$ ), marginal revenues are positive for any price above $p_{i}^{D}(p)$ and negative below. Hence, firm $i$ quotes the price $p_{i}^{D}(p)$. This argument yields the following candidate for firm $i$ 's best response function:

$$
R(p)=\left\{\begin{array}{llll}
p_{i}^{\ell *} & \text { if } \quad 0 \leq p<p^{f}, & \text { (Blockading piracy) } \\
p_{i}^{D}(p) & \text { if } \quad p^{f}<p \leq p^{d}, & \text { (Deterring } \alpha \text {-reversing users) } \\
p_{i}^{\alpha *}(p) & \text { if } \quad p^{d}<p . & \text { (Accommodating } \alpha \text {-reversing users) }
\end{array}\right.
$$

This function applies provided that users consist only of loyal and $\alpha$-reversing users and that no other regime is more profitable. The following lemma is now trivial.

Lemma 4 There exists a price of the other goods $\widehat{p}_{1}>p^{f}$ such that each firm's best response is $R_{i}^{*}(p)=R(p)$ for $p \in\left[0, \widehat{p}_{1}\right]$.

This lemma establishes the following points. First, blockading is a symmetric equilibrium if $p_{i}^{\ell *} \leq p^{f}$. Using the above values, we get the condition $A C(n) / s_{c} \geq \bar{\theta} / 2$. Second, there always exists a range of price $p$ such that firm $i$ 's best response is to quote an $\alpha$-reversing user deterrence price. This last point does not mean, nevertheless, that an equilibrium exists for which all firms quote the same $\alpha$-reversing user deterrence price. In other words, an equilibrium involving deterrence of $\alpha$-reversing users may fail to exist. The candidate symmetric equilibrium is given by the fixed point of $p_{i}^{D}(p)=p$. Simple computations show that this price is equal to $p_{i}=p=A C(n) s_{o} / s_{c}$. In 
the case of bad copies, we have argued above that for $p=A C(n) s_{o} / s_{c}$, firm $i$ 's price function coincides with the inverse demand function of loyal users. Therefore, firm $i$ 's optimum is to set $p_{i}^{\ell *}$ and we do not have an equilibrium with deterrence of $\alpha$-reversing users. In the case of good copies, on the other hand, $p_{i}^{\alpha}(\theta, p)$ may intersect with $p_{i}^{\ell}(\theta)$, which implies that it is possible to have an equilibrium involving deterrence of $\alpha$-reversing users. One condition is that $p^{f}<A C(n) s_{o} / s_{c}$, which is equivalent to $A C(n) / s_{c}<\bar{\theta} / 2$ (i.e., blockading is not a symmetric equilibrium). We summarize our results in the next proposition.

Proposition 2 Blockading piracy is a symmetric equilibrium for good and bad copies if and only if $A C(n) / s_{c} \geq \bar{\theta} / 2$. Deterrence of $\alpha$-reversing users is never a symmetric equilibrium if copies are bad.

As it will be shown in the following sections, best response functions can take different shapes for values of $p$ above $\widehat{p}_{1}$. However, when the price $p$ of other originals is sufficiently large, the firm's behavior is readily determined.

\subsection{Attitude towards general piracy}

When the price $p$ of other originals is sufficiently large, users are definitively not attracted by originals and they engage in piracy. In this case, firm $i$ does not find it profitable to set a high price: it prefers to quote a lower price and to accommodate piracy of its own original. This regime embeds several complications because the firm may face multiple types of pirates: copying users, as well as $\alpha$ - or $\beta$-reversing users. However, a relatively clearer picture appears when the price $p$ of other originals passes some threshold, so that the $\alpha$ reversing behavior becomes dominated by $\beta$-reversing or copying. We identify this threshold as $p^{g}$ such that $p_{i}^{\alpha}\left(p^{g}, \bar{\theta}\right)=\max \left\{p_{i}^{c}(\bar{\theta}), p_{i}^{\beta}(\bar{\theta})\right\}$. In Figures 1 and 2 , we have represented the case where $p_{i}^{c}(\bar{\theta})>p_{i}^{\beta}(\bar{\theta})$ and $p_{i}^{\alpha}\left(p^{g}, \theta\right)$ is the price function that intersects schedule $p_{i}^{c}$ at $\theta=\bar{\theta}$. Therefore, for $p \geq p^{g}$, there exists no $p_{i}$ that can make $\alpha$-reversing users purchase original $i$. Firm $i$ faces the 'lowest envelop of the price function', which is depicted by the grey bold line in Figures 1 and 2 and which can be written as:

$$
p_{i}^{E}(\theta) \equiv \min \left\{p_{i}^{\ell}(\theta), \max \left[p_{i}^{c}(\theta), p_{i}^{\beta}(\theta)\right]\right\} .
$$

Maximization of profit over $p_{i}^{E}(\theta)$ yields the optimum price and profit, $p_{i}^{E *}$ and $\pi_{i}^{E *}$. It follows that when the other originals are more expensive than $p^{g}$, firm $i$ 's best response is to set $p_{1}^{E *}$. At this stage, we take $p_{i}^{E *}$ and $\pi_{i}^{E *}$ as implicitly determined and we can state the following proposition. ${ }^{7}$

\footnotetext{
${ }^{7}$ The exact characterization of $p_{i}^{E} *$ and $\pi_{i}^{E *}$ is cumbersome as the demand function can combine different types of consumers. Explicit computations are provided in the Section 6 under some simplifying assumptions.
} 
Proposition 3 There exists a price of the other goods, $\widehat{p}_{2}$, such that each firm's best response is $R_{i}^{*}(p)=p_{i}^{E *}$ for $p \in\left[\widehat{p}_{2}, \infty\right)$. Furthermore, $\widehat{p}_{2} \leq p^{g} \equiv$ $\min \left\{A C(n-1)+\left(s_{o}-s_{c}\right) \bar{\theta}, s_{o} \bar{\theta}\right\}$.

Proof. The fact that $R_{i}^{*}(p)=p_{i}^{E *}$ when $p \geq p^{g}$ has been exposed above. By continuity, any $p$ smaller than $p^{g}$ also yields $R_{i}^{*}(p)=p_{i}^{E *}$ except in the particular case where $p_{i}^{E *}=p^{g}$ which implies that $\widehat{p}_{2}=p^{g}$. Finally, the value of $p^{g}$ is determined by solving $p_{i}^{\alpha}\left(p^{g}, \bar{\theta}\right)=p_{i}^{c}(\bar{\theta})$ and $p_{i}^{\alpha}\left(p^{g}, \bar{\theta}\right)=p_{i}^{\beta}(\bar{\theta})$.

Can this regime can be associated with a symmetric equilibrium? Intuitively, if all other firms set a high price and entice users to pirate, the best response for a single firm is to set a low price and accommodate piracy. It is therefore likely that firms do not set the same price. This is certainly true when the price of other originals is larger than any feasible price for firm $i$ : that is, when $p>\max _{\theta} p_{i}^{E}(\theta)$. The following proposition indicates an upward limit on the equilibrium price sustaining the current regime.

Proposition 4 If the price of the other originals is larger than $p^{g}$, then there are no $\alpha$-reversing users and accommodation of piracy is never a symmetric equilibrium.

Proof. See the appendix.

\subsection{Jumps in the best response function}

Kinks in the demand function have been identified above. The possibility of convex kinks implies downward jumps in the best response functions for prices $p$ of other originals in the interval $\left[\widehat{p}_{1}, \widehat{p}_{2}\right]$. Downward jumps can lead to the absence of equilibria for some configurations of economic parameters. Because more than one convex kinks may appear for prices $p \in\left[\widehat{p}_{1}, \widehat{p}_{2}\right]$, the analysis of the best response function in this interval is complex.

The analysis is simplified when the 'lowest envelop of the price function' $p_{i}^{E}(\theta)$ does not include $\beta$-reversing users, meaning that expression (5) boils down to

$$
\bar{p}_{i}^{E}(\theta) \equiv \min \left\{p_{i}^{\ell}(\theta), p_{i}^{c}(\theta)\right\} .
$$

In the sequel, we examine two classes of examples satisfying this requirement. First, we focus on the case where the number of varieties is sufficiently large so that the average cost of copying the last original is a constant: $A C(n)=A C(n-1)=C^{\prime}(n)$. Second, we focus on users with a sufficiently high valuation for originals and copies (i.e., we assume that $\underline{\theta} \geq A C(n-1) / s_{c}$ ). These examples are shown in the two panels of Figure 3. 

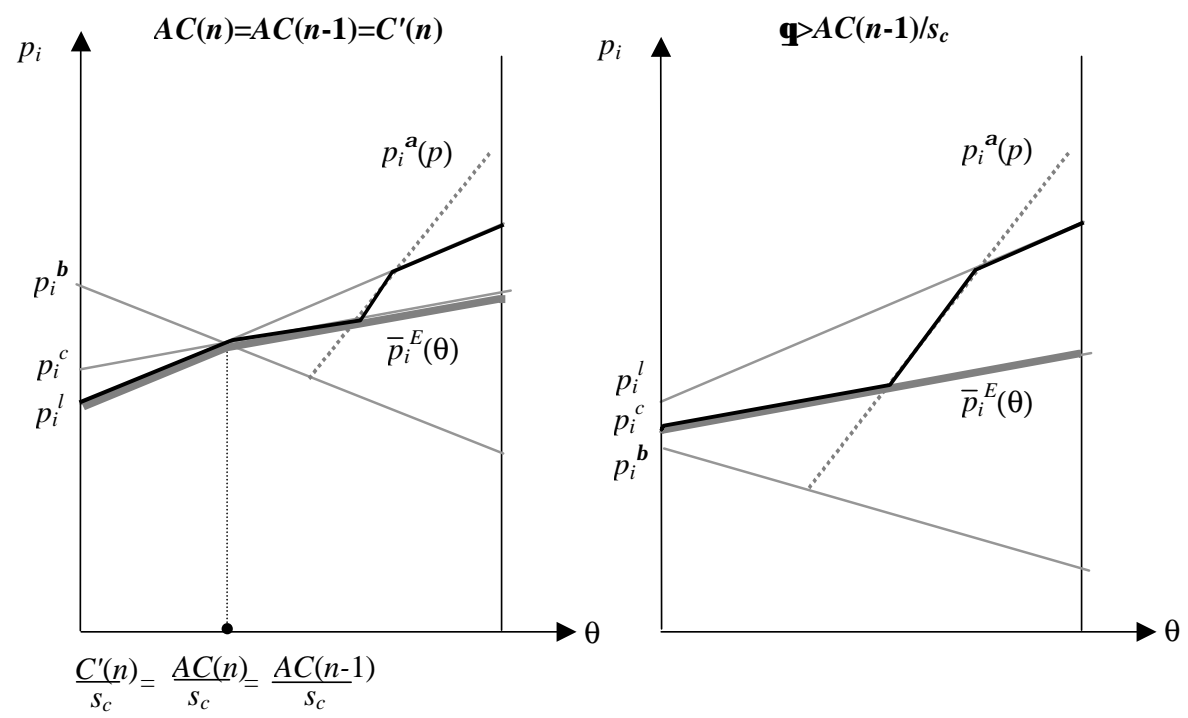

Figure 3: Price function for many goods and for users with high valuation

In this simpler case, optimal price and profit under $\bar{p}_{i}^{E}(\theta)$ are equal to the cartel price and profit as determined in Proposition 1. In addition, a unique convex kink appears at the 'copying/ $\alpha$-reversing' user, $\theta_{\alpha c}(p)$, which increases in $p$. As the price of other originals rises, the profit under deterrence or accommodation of $\alpha$-reversing users decreases and reaches the level of profit obtained under accommodation of copying users. The price instantaneously jumps from the high or intermediate price down to a lower price. We derive the following property.

Lemma 5 Suppose that the lowest envelop of the price function is equal to $\bar{p}_{i}^{E}(\theta) \equiv \min \left\{p_{i}^{\ell}(\theta), p_{i}^{c}(\theta)\right\}$. Then, the interval $\left[\widehat{p}_{1}, \widehat{p}_{2}\right]$ collapses to a single point, $\widehat{p}$. The best response function has no jump at $\widehat{p}$ if copies are good and if $\widehat{p} \in\left[p^{f}, p^{d}\right]$. Otherwise, the best response function has a downward jump at $\widehat{p}$.

Proof. See the appendix.

The lemma reveals that in the case of good copies and $\widehat{p} \in\left[p^{f}, p^{d}\right]$, the graph of the best response function is continuous and a symmetric equilibrium exists. Still, although the lemma provides a rather complete description of best response functions, it remains to determine the value of $\widehat{p}$.

\section{Symmetric equilibria in specific settings}

We now turn to the two classes of examples we mentioned above. They allow us to proceed further in the study of symmetric equilibria. 


\subsection{Many varieties}

In this section, we focus on the case where the number of varieties is large. It is therefore natural to assume that the average cost of copying the last original is a constant, and to restrict the attention to bad copies.

Assumption $3 A C(n)=A C(n-1)=C^{\prime}(n)$ and $n s_{c}<(n-1) s_{o}$.

This simplification allows us to consider a wide range of user valuations. In particular, we do not want to exclude low valuation users (i.e., users who are not willing to purchase or copy any good) and we impose:

\section{Assumption $4 \underline{\theta}=0$.}

Under assumption 3, users can never be ' $\beta$-reversing users': they are either loyal, $\alpha$-reversing or copying users. Accommodation of copying users can yield the three prices $p_{i}^{E *} \in\left\{p_{i}^{\ell *}, p_{i}^{c *}, p_{i}^{C}\right\}$, which are the prices $\left\{p^{\ell *}, p^{c *}, p^{C}\right\}$ set by the cartel because $C^{\prime}(n)=A C(n)$ under Assumption 3. Lemma 5 can then be applied. Each firm chooses amongst four strategies: blockading, deterrence of $\alpha$-reversing users, accommodation of $\alpha$-reversing users or of copying users. From Proposition 2, we already know that blockading is the unique symmetric equilibrium when $\bar{\theta} / 2 \leq A C(n) / s_{c}$, and that deterrence is never a symmetric equilibrium when copies are bad. We thus only need to check whether there exist equilibria with accommodation of $\alpha$-reversing users or of copying users. Yet, it turns out that these regimes never yield symmetric equilibria. In particular, when the other firms choose to accommodate $\alpha$-reversing users, it is optimal for firm $i$ to accommodate copying users. Conversely, when the other firms choose to accommodate copying users, it is optimal for firm $i$ to accommodate $\alpha$-reversing users. As a result, there exists no symmetric equilibrium when $\bar{\theta} / 2>A C(n) / s_{c}$.

Proposition 5 Under Assumptions 3 and 4, blockading piracy is the unique symmetric equilibrium if $A C(n) / s_{c} \geq \bar{\theta} / 2$. Otherwise there exists no symmetric equilibrium.

Proof. See the appendix.

The inexistence of symmetric equilibria stems from firms' free-riding behavior with respect to the threat of piracy. If all firms takes this threat seriously and quote low prices to accommodate users, then they put a price too low and there exists an opportunity for a single firm to raise its price while keeping a sufficiently large demand and making a larger profit. Our assumption of a significant number of users with very low value for originals and copies drives the above result of absence of equilibria. As the next example shows, more equilibria may exist when users highly value originals and copies. 


\subsection{High valuation users}

In this section, we assume that users have a high valuation for originals and copies. More specifically, we assume that no user ever finds it optimal to refrain from using any information good:

Assumption $5 \underline{\theta} s_{c} \geq A C(n-1)$.

Under this assumption, the 'lowest envelop of the price function' $p_{i}^{E}(\theta)$ is equal to $p_{i}^{c}(\theta)$. The optimal price is equal to $p_{i}^{E *}=\max \left\{p_{i}^{c *}, p_{i}^{c}(\underline{\theta})\right\}$. For simplicity, we assume interior solution $\left(p_{i}^{E *}=p_{i}^{c *}\right)$ which is guaranteed by the following assumption:

Assumption $6 \bar{\theta}>2 \underline{\theta}+C^{\prime}(n) /\left(s_{o}-s_{c}\right)$.

Lemma 5 can be now applied. The price $\widehat{p}$ is found by comparing profit levels under $\alpha$-reversing user deterrence and accommodation regimes with those under the accommodation of copying users.

Let us characterize the best response function. There are two possible cases according to whether $\widehat{p}$ is below or above $p^{d}$. As shown in the appendix, the price $\widehat{p} \equiv \widehat{p}^{\prime}$ is above $p^{d}$ if

$$
C^{\prime}(n)<C_{0}^{\prime} \equiv \frac{\left(n s_{c}-(n+1-2 \sqrt{n}) s_{o}\right)\left(s_{o}-s_{c}\right)}{(n+1) s_{o}-n s_{c}} \bar{\theta} .
$$

In this case, the best response function is equal to

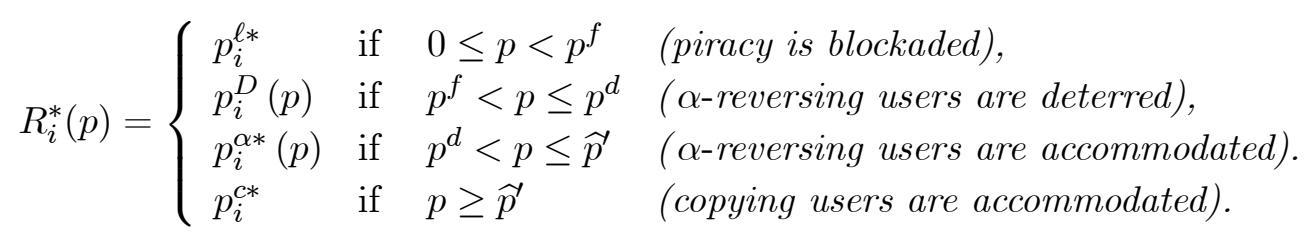

where $\widehat{p}^{\prime} \equiv p^{d}+\frac{\sqrt{n}}{n-1}\left[C_{0}^{\prime}-C^{\prime}(n)\right]$. Otherwise, the price $\widehat{p} \equiv \widehat{p}^{\prime \prime}$ is below $p^{d}$ and the best response function writes as

$$
R_{i}^{*}(p)=\left\{\begin{array}{lll}
p_{i}^{\ell *} & \text { if } \quad 0 \leq p<p^{f} \quad \text { (piracy is blockaded), } \\
p_{i}^{D}(p) & \text { if } p^{f}<p \leq \widehat{p}^{\prime \prime} \quad \text { ( } \alpha \text {-reversing users are deterred) } \\
p_{i}^{c *} & \text { if } \quad p \geq \widehat{p}^{\prime \prime} & \text { (copying users are accommodated) }
\end{array}\right.
$$

where $\widehat{p}^{\prime \prime} \equiv p^{d}-\frac{1}{2(n-1)}\left[F\left(C^{\prime}(n)\right)-F\left(C_{0}^{\prime}\right)\right]$ and

$$
F\left(C^{\prime}(n)\right) \equiv \sqrt{\frac{\left(s_{c}\left(s_{o}-s_{c}\right) \bar{\theta}^{2}-2 C^{\prime}(n)\left(s_{o}-s_{c}\right) \bar{\theta}-C^{\prime}(n)^{2}\right)\left((n-1) s_{o}-n s_{c}\right)^{2}}{s_{o}\left(s_{o}-s_{c}\right)}} .
$$

We now turn to the characterization of symmetric equilibria and examine the four possible regimes. 
Blockading piracy. Combining Proposition 2 and Assumption 5 and 6, we readily infer that blockading piracy cannot be a symmetric equilibrium. Because not only high but also low valuation users get a large utility from copies, piracy exerts such a threat that blockading is not feasible.

Deterrence of $\alpha$-reversing users. We know from Proposition 2 that deterrence of $\alpha$-reversing users is not an equilibrium under bad copies. In contrast, under good copies, there exist parameter configurations supporting symmetric equilibria with deterrence. We show in the appendix that under good copies, Assumption 6 implies that $C^{\prime}(n)<C_{0}^{\prime}$, so that $\widehat{p}>p^{d}$. The conditions for a symmetric equilibrium are: $p_{i}^{D}\left(p^{f}\right) \leq p^{f}$ and $p_{i}^{D}\left(p^{d}\right) \leq p^{d}$, which write as

$$
\frac{1}{2} \bar{\theta}\left(1-\frac{n s_{c}-(n-1) s_{o}}{(n+1) s_{o}-n s_{c}}\right) \leq A C(n) / s_{c}<\frac{1}{2} \bar{\theta} .
$$

It is easily checked that the interval is open.

Accommodation of $\alpha$-reversing users. This strategy is feasible if and only if $C^{\prime}(n)<C_{0}^{\prime}$, , under which $\widehat{p}=\widehat{p}^{\prime}<p^{d}$. In this case, there are two conditions for a symmetric equilibrium:

$$
\left\{\begin{array}{l}
p^{d} \leq p_{i}^{D}\left(p^{d}\right) \Longleftrightarrow A C(n) \leq \frac{1}{2} \bar{\theta} s_{c}\left(1-\frac{n s_{c}-(n-1) s_{o}}{(n+1) s_{o}-n s_{c}}\right) \\
\widehat{p}^{\prime} \geq p_{i}^{\alpha *}\left(\widehat{p}^{\prime}\right) \Longleftrightarrow A C(n) \geq \frac{(n+1) \sqrt{n}-2 n}{2 n} \bar{\theta}\left(s_{o}-s_{c}\right)+\frac{(n+1) \sqrt{n}}{2 n} C^{\prime}(n) .
\end{array}\right.
$$

We show in the appendix that $C^{\prime}(n)<C_{0}^{\prime}$ makes sure that the latter two inequalities are compatible.

Accommodation of copying users. Copying users are accommodated when firms set the price $p_{i}^{c *}$. We know that accommodation of copying users is never a symmetric equilibrium if the price of the other originals is above $p^{g}$. Under the particular assumptions of this section, we can get a necessary and sufficient condition. Accommodation of copying users occurs if and only if $p_{i}^{c *}$ is larger than $\hat{p}^{\prime}$ or $\widehat{p}^{\prime \prime}$. When $C^{\prime}(n)<C_{0}^{\prime}$, optimal profit and price under accommodation are low. Given the low price of competitors, each individual firm has an incentive to deviate (by setting a higher price). Indeed, it can be shown analytically that $p_{i}^{c *}<\widehat{p}^{\prime}$ for all admissible configurations of parameters, meaning that accommodation of copying users cannot be a symmetric equilibrium when $C^{\prime}(n)<C_{0}^{\prime}$. Otherwise, accommodation of copying users can be a symmetric equilibrium. It is so if and only if $p_{i}^{c *} \geq \widehat{p}^{\prime \prime}$, which is equivalent to

$$
A C(n) \leq \frac{1}{2 n} \bar{\theta} s_{c}+\frac{n-1}{2 n} C^{\prime}(n)-\frac{F\left(C^{\prime}(n)\right)}{2 n} .
$$

We cannot guarantee that the latter inequality is satisfied under the assumptions of this section. 


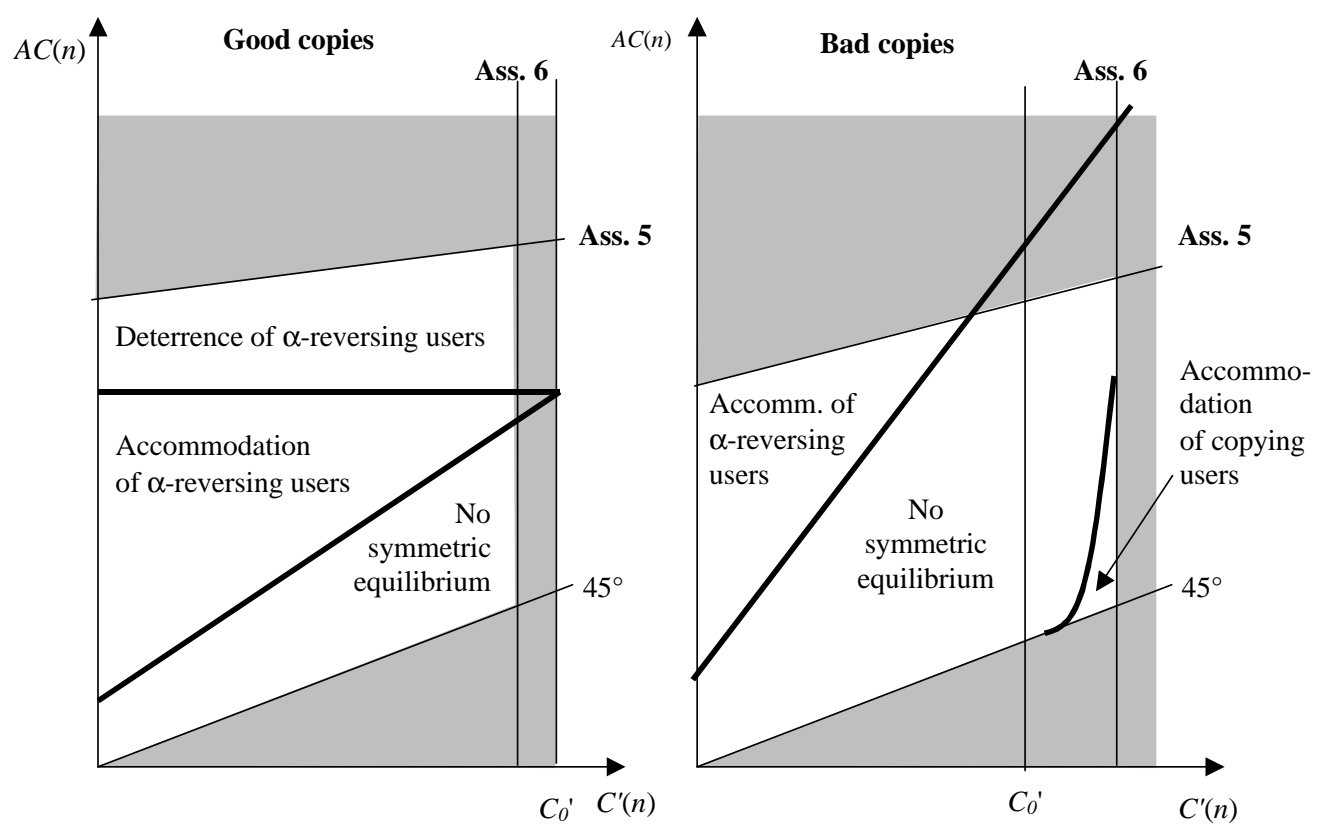

Figure 4: Characterization of symmetric equilibria for good and bad copies

The previous results are illustrated in Figure 4 for selected values of the parameters.

Discussion. Our initial restrictions on the economic parameters make sure that, at the symmetric equilibrium of the game, the producers of information goods are affected by the users' ability to make copies; indeed, there cannot be an equilibrium where all producers behave as unconstrained local monopolists. The question is then how producers modify their pricing behavior in the face of copying. As depicted in Figure 4, the answer crucially depends on the properties of the copying technology: that is, on the relative importance of the average and marginal costs of copying $\left(A C(n)\right.$ vs. $\left.C^{\prime}(n)\right)$, and on the relative quality of copies ( $s_{c}$ vs. $\left.s_{o}\right)$.

Consider first good copies. In this case, two different attitudes can emerge at the symmetric equilibrium. If the copying technology exhibits important returns to scale (large average costs and small marginal costs), firms find it profitable to deter copying: they set a price for their information product which is low enough to make copying unprofitable for all users. For copying technologies with lower returns to scale, the latter option is too costly and firms prefer therefore to tolerate copying: they accommodate ' $\alpha$-reversing users' (i.e., those users who contemplate purchasing or copying all goods). Finally, if the marginal cost of copying is low and close enough to the average cost, the copying technology exhibits weak returns to scale and a symmetric equilibrium fails to exist. The 
reason for such inexistence is the following. When all other firms choose to accommodate $\alpha$-reversing users by setting a relatively high price, users consider that originals have become so expensive that copying (using a rather cheap technology) is preferable. As a result, any individual firm has an incentive to deviate by setting a lower price and accommodating instead the copying users.

Consider now bad copies. Although, other things being equal, copying is less attractive than in the previous case, it turns out that there is no symmetric equilibrium where firms manage to deter copying. To understand this seemingly paradoxical result, it must be recalled that with bad copies, each firm must set a high enough price to deter users from reversing their purchase decision. In contrast with the case of high-quality copies, a firm's individual deterrence price increases with the price set by the other producers. As a result, the section of a firm's best-response function where deterrence is the optimal conduct is upward-sloping (meaning that prices become strategic substitutes) and reaches prices which are above the unconstrained monopoly price. Yet, the assumptions of the present section prevent the monopoly price to be part of a symmetric equilibrium and, by the same token, so do they for any higher price. This explains why there is no symmetric deterrence equilibrium for bad copies. Two possible attitudes remain. For a sufficiently high average cost of copying, there is a symmetric equilibrium where producers tolerate copying: they accommodate reversing users for a sufficiently low marginal cost of copying, or copying users otherwise.

\subsection{Comparison with the cartel case}

In this paper we have shown that firms' equilibrium strategies significantly differ under oligopolistic competition than under cartels setting a unique price. Whereas the cartel can blockade piracy, deter copying users or accommodate copying users, oligopolistic firms may choose to blockade piracy, deter $\alpha$-reversing users, accommodate $\alpha$-reversing users and blockade copying users. In the oligopoly, individual firms are able to free ride on each other by extracting some additional copiers or buyers' surplus which cannot be appropriated through the single price of the cartel. This leads to several implications.

First, in contrast to cartels, there often exists no equilibrium with a symmetric (single) price in oligopolies. Second, symmetric prices in oligopolies (if they exist) can exceed the cartel's price. For instance, when users have high valuations for originals and copies, cartels choose to accommodate copying users and oligopolies can yield symmetric equilibria with accommodation of $\alpha$-reversing users (see Figure 4). The prices are given by $p^{c *}$ for the cartel (see Proposition 1) and by $p_{i}^{\alpha *}(p)=p$ for the oligopoly. We readily get that

$$
p^{c *}=\frac{1}{2}\left[\left(s_{o}-s_{c}\right) \bar{\theta}+A C(n)\right]<\frac{n}{n+1}\left[\left(s_{o}-s_{c}\right) \bar{\theta}+A C(n)\right]=p
$$

This result is true whether copies are good or bad. 
Third, oligopolies can yield symmetric equilibria with deterrence of $\alpha$-reversing users whereas cartels may never choose to deter. For example, when users have high valuations for originals and copies, cartels choose to accommodate copying users although oligopolies may yield equilibria with deterrence of $\alpha$-reversing users (see good copies in Figure 4). In oligopolies, the deterrence price can be above or below the cartel price.

\section{Conclusion}

Information goods fall in the category of public goods with exclusion, that is, "public goods the consumption of which by individuals can be controlled, measured and subjected to payment or other contractual limitation" (Drèze, 1980). Exclusion can be achieved through legal authority and/or technical means. However, simply specifying intellectual property laws does not ensure that they will be enforced; similarly, technical protective measures are often imperfect and can be "cracked". As a result, illicit copying (or piracy) cannot be completely avoided. It is therefore extremely important to understand how copying affects the demand for legitimate information goods and the pricing behavior of their producers. In particular, closer attention must be devoted to the strategic interaction among producers, which results from increasing returns to scale in the copying technology. The users' decision to invest in such technology is based, indeed, on a comparison between the cost of the copying equipment and the prices of all the goods that can be copied. The demand for a particular original is therefore indirectly affected by the prices of other originals.

The present paper addresses this issue within a simple, unified model of competition between originals and copies. We use the vertical differentiation framework proposed by Mussa and Rosen (1978): copies are seen as lowerquality alternatives to originals. We characterize the symmetric Nash equilibria of the pricing game played by $n$ oligopolists (each one controlling one good). Using the terminology of Bain (1956), we show that under cartels, piracy will be blockaded, deterred (through symmetric limit-pricing) or accommodated. Under oligopolistic competition, firms' equilibrium strategies significantly differ than those under cartels. An oligopolistic firm may indeed choose to blockade piracy and blockade copying users as cartels but it can also choose to free ride on other firms by extracting some additional copiers or buyers' surplus which cannot be appropriated through the single price of the cartel. In these two last strategies, the firm sets its prices according to the valuations of users who are enticed to reverse their copying decision because of the free riding firm's price. By setting a price different from other firms, a fre-riding firm is able to increase its profit either by increasing its price when competitors set a low price or by reducing its price and increasing its own demand when competitors set high prices. As a result, oligopolies may have no symmetric equilibria; when they 
do, they may end up with higher prices than in the cartel.

\section{References}

[1] Bae, S.H. and Choi, J.P. (2003). A model of piracy. Mimeo. Michigan State University.

[2] Bain, J. (1956). Barriers to new competition. Harvard Business Press, Cambridge (Mass.).

[3] Belleflamme, P. (2002). Pricing information goods in the presence of copying. Working Paper No. 463, Queen Mary University of London.

[4] Drèze, J.H. (1980). Public goods with exclusion. Journal of Public Economics 13: 15-24.

[5] Gayer, A. and Shy, O. (2003). Copyright protection and hardware taxation. Information Economics and Policy 15: 467-483.

[6] Johnson, W.R. (1985). The economics of copying. Journal of Political Economy 93: 158-174.

[7] Koboldt, C. (1995). Intellectual property and optimal copyright protection. Journal of Cultural Economics 19: 131-155.

[8] Mussa, M., and Rosen, S. (1978). Monopoly and product quality. Journal of Economic Theory 18: 301-317.

[9] Peitz, M. and Waelbroeck, P. (2003). Piracy of digital products: A critical review of the economics literature. CESifo Working Paper No. 1071.

[10] Plant, A. (1934). The economic aspects of copyright in books. Economica 1: 167-195.

[11] Varian, H.R. (1998). Markets for information goods. Mimeo, University of California, Berkeley.

[12] Watt, R. (2000). Copyright and Economic Theory. Friends or Foes? Edward Elgar Publishing, Cheltenham (UK) and Northampton (Mass.).

[13] Yoon, K. (2002). The optimal level of copyright protection. Information Economics and Policy 14: 327-348. 


\section{Appendix}

\subsection{Proof of Proposition 4}

We must show that $p^{g} \geq \max _{\theta} p_{i}^{E}(\theta)$. Note first that $A C(n-1) / s_{c}<\bar{\theta}$ is equivalent to $p_{i}^{c}(\bar{\theta})>p_{i}^{\beta}(\bar{\theta})$ and implies that $p^{g}=A C(n-1)+\left(s_{o}-s_{c}\right) \bar{\theta}<s_{o} \bar{\theta}$. Then, it can be observed that the function $p_{i}^{E}(\theta)$ reaches a local maximum at $p_{i}=p_{i}^{\ell}\left(A C(n) / s_{c}\right)$ and $\theta=A C(n) / s_{c}$ and, that it reaches another local maximum either at $p_{i}=p_{i}^{c}(\bar{\theta})$ and $\theta=\bar{\theta}$ or at $p_{i}=p_{i}^{\beta}(\bar{\theta})$ and $\theta=\bar{\theta}$ according to whether $p_{i}^{c}(\bar{\theta})>p_{i}^{\beta}(\bar{\theta})$ or not. We check two cases accordingly. On the one hand, suppose that $p_{i}^{c}(\bar{\theta})>p_{i}^{\beta}(\bar{\theta}) \Longleftrightarrow A C(n-1) / s_{c}<\bar{\theta}$. Then, we must check that the conditions $p^{g}=A C(n-1)+\left(s_{o}-s_{c}\right) \bar{\theta}>p_{i}^{\ell}\left(A C(n) / s_{c}\right)$ and $p^{g}=$ $A C(n-1)+\left(s_{o}-s_{c}\right) \bar{\theta}>p_{i}^{c}(\bar{\theta})$ are satisfied. The first condition is indeed satisfied because, by Assumption 2, we have that $s_{c} \bar{\theta}>A C(n) \Longleftrightarrow\left(s_{o}-s_{c}\right) \bar{\theta}>$ $A C(n) s_{o} / s_{c}-A C(n)$, which implies $\left(s_{o}-s_{c}\right) \bar{\theta}>A C(n) s_{o} / s_{c}-A C(n-1)$ $\Longleftrightarrow . A C(n-1)+\left(s_{o}-s_{c}\right) \bar{\theta}>A C(n) s_{o} / s_{c}=p_{i}^{\ell}\left(A C(n) / s_{c}\right)$. The second condition is satisfied because, by Assumption 1, we get that $A C(n-1) \geq A C(n) \Longleftrightarrow$ $A C(n-1) \geq C^{\prime}(n) \Longleftrightarrow A C(n-1)+\left(s_{o}-s_{c}\right) \bar{\theta} \geq C^{\prime}(n)+\left(s_{o}-s_{c}\right) \bar{\theta}=p_{i}^{c}(\bar{\theta})$. On the other hand, suppose that $p_{i}^{c}(\bar{\theta})<p_{i}^{\beta}(\bar{\theta}) \Longleftrightarrow A C(n-1) / s_{c}>\bar{\theta}$. Then

we must simply check that $s_{o} \bar{\theta}>\max \left\{p_{i}^{\ell}\left(A C(n) / s_{c}\right), p_{i}^{\beta}(\bar{\theta})\right\}$, which is always true by Assumption 2.

\subsection{Proof of Lemma 5}

When the lowest envelop of the price function is equal to $\bar{p}_{i}^{E}(\theta) \equiv \min \left\{p_{i}^{\ell}(\theta), p_{i}^{c}(\theta)\right\}$, the price function itself writes as $p_{i}(\theta)=\min \left\{p_{i}^{\ell}(\theta), \max \left[p_{i}^{c}(\theta), p_{i}^{\alpha}(\theta, p)\right]\right\}$. It has only two possible concave kinks at $\theta_{\alpha \ell}(p)$ and $\theta_{l c}$ and possibly another convex kink at $\theta_{\alpha c}(p)$. The graph of the demand function is the same as the graph of the price function (after inversion of the horizontal axis). Given this configuration, it is easily seen that, as $p$ increases, firm $i$ 's best response can jump only once. Therefore, the interval $\left[\widehat{p}_{1}, \widehat{p}_{2}\right]$ collapses to a single point, say $\widehat{p}$.

The direction of the jump is given by the two following statements about optimal price and profit under linear demand functions. Construct two linear demand functions. First, if both demand functions yield the same optimal unconstrained profit, the optimal price is higher under the steeper function. This statement is no longer correct if the optimal profit is constrained. Second, let us consider the locus of the optimal price and quantity for each demand schedule when they are shifted in a parallel way. Then, the locus of optimal prices and quantities goes through the origin, and the locus of the steeper demand curve is also steeper.

Consider the possible price strategies under $\bar{p}_{i}^{E}(\theta)$. First, if the optimal strategy is $\bar{p}_{i}^{E *}=p^{\ell *}$, then the best response is $p^{\ell *}$ for all $p$ and there is no 
deterrence or accommodation regime. We need only to consider $\bar{p}_{i}^{E *}=p^{c *}$ or $p^{C}$. Let us draw the price functions and the locus of reversing user accommodation for all possible $p$ (i.e., $\Phi(p, \theta)$, the optimal price and quantity under $\left.p_{i}^{\alpha}(p, \theta)\right)$. Let us also draw the iso-profit curve passing through either $p^{c *}$ or $p^{C}$. In the case of bad copies, the locus of reversing user accommodation passes on the right-hand side of the optimal prices and quantities related to $p_{i}^{\ell *}, p^{c *}$ and $p^{C}$. It is easily shown that there exists a downward jump (see the top panels in Figure 5). In the case of good copies, the locus of reversing user accommodation passes on the left-hand side of the optimal price and quantity related to $p_{i}^{\ell *}$, and on the right hand side of the price and quantity related to $p^{c *}$. If $\bar{p}_{i}^{E *}=p^{c *}$, then we have that $p^{c *}>p^{C}$ and that the locus of reversing user accommodation lies between the prices and quantities associated to $p_{i}^{\ell *}$ and $p^{c *}$. Drawing the iso-profit curve associated to $p^{c *}$, it can readily been shown that accommodation of reversing users always exists and that the best response function has a downward jump from $p_{i}^{\alpha *}(\widehat{p})$ to $p^{c *}$ (see the bottom-left panel in Figure 5). Finally if $\bar{p}_{i}^{E *}=p^{C}$, then we have that $p^{c *}<p^{C}$. Two situations occur. On the one hand, the locus of reversing user accommodation can be located to the left-hand side of the price and quantity associated with $p^{C}$, and the best response function continuously decreases in the reversing user regime down to $p^{C}$. No jump occurs (see the bottom-right panel in Figure 5). The condition for this situation is obviously that $\widehat{p} \in\left[p^{f}, p^{d}\right]$. On the other hand, the locus of reversing user accommodation can be located on the right-hand side of the price and quantity associated with $p^{C}$. As $p$ increases, the best response function must switch from the reversing user regime to the accommodation regime before discontinuously moving downward from $p_{i}^{\alpha *}(\widehat{p})$ to $p^{c *}$ (as in the bottom-left panel in Figure 5).

\subsection{Proof of Proposition 5}

(i) If the other firms choose to accommodate $\alpha$-reversing users, then firm $i$ makes a larger profit by accommodating copying users at price $p_{i}^{E *}$ than by accommodating $\alpha$-reversing users. The fixed point under accommodation of $\alpha$-reversing users solves the equation $p=p^{\alpha *}(p)$ and yields the following price and profit

$$
p^{a *}=\frac{n}{n+1}\left(A C(n)+\left(s_{o}-s_{c}\right) \bar{\theta}\right) \quad \text { and } \quad \pi^{a *}=\frac{n\left(A C(n)+\left(s_{o}-s_{c}\right) \bar{\theta}\right)^{2}}{(n+1)^{2}\left(s_{o}-s_{c}\right)(\bar{\theta}-\underline{\theta})}
$$

On the one hand, consider that $p_{i}^{E *}=p^{c *}=\frac{1}{2}\left(A C(n)+\left(s_{o}-s_{c}\right) \bar{\theta}\right)>p^{C}$ which yields the following profit level:

$$
\pi^{c *}=\frac{\left(A C(n)+\left(s_{o}-s_{c}\right) \bar{\theta}\right)^{2}}{4\left(s_{o}-s_{c}\right)(\bar{\theta}-\underline{\theta})} .
$$



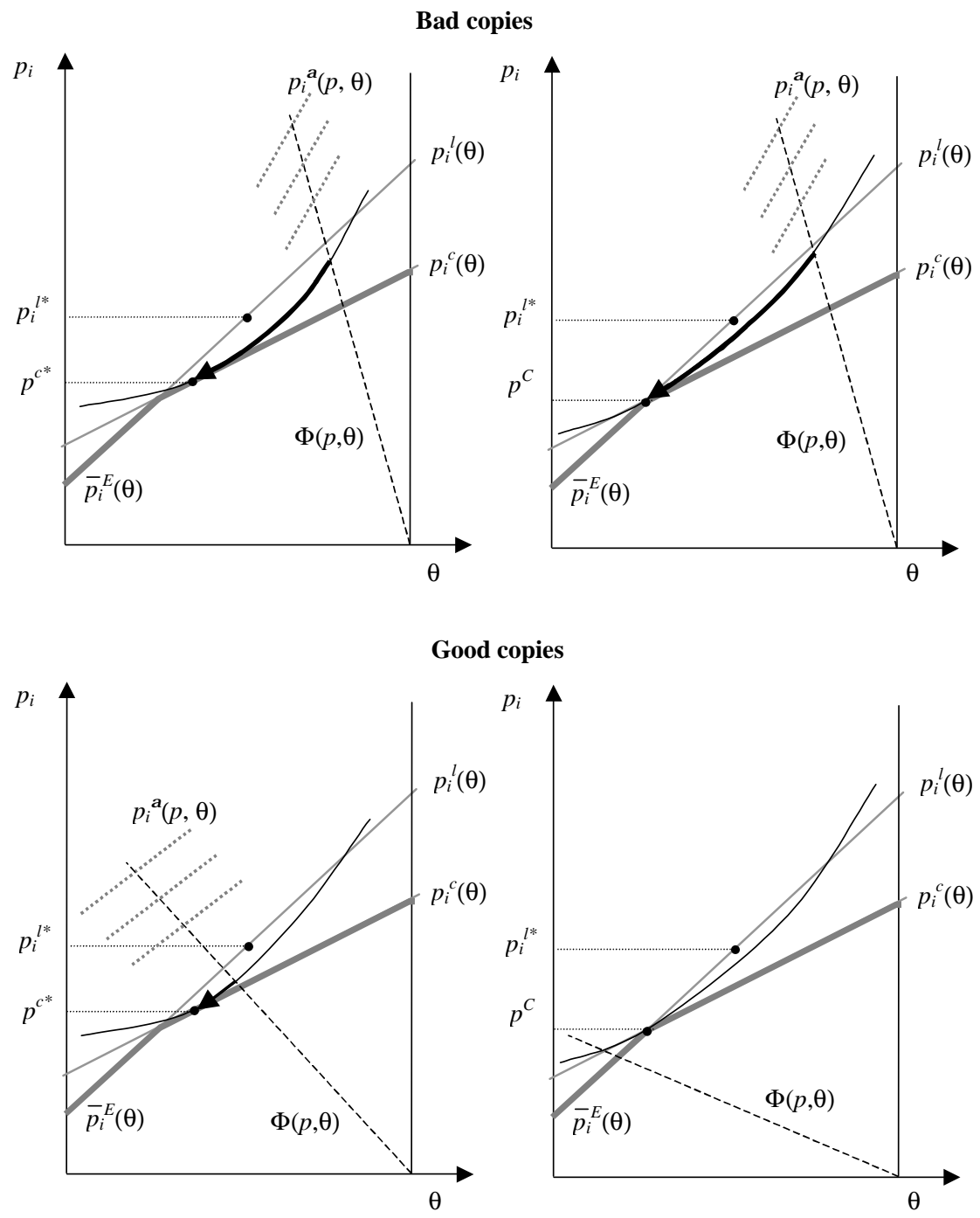

Figure 5: Jumps in optimal prices 
Some algebraic manipulations show that $\pi^{c *}>\pi^{a *}$ and thus that accommodating copying users is more profitable. On the other hand, consider that $p_{i}^{E *}=p^{C}=\left(s_{o} / s_{c}\right) A C(n)>p^{c *}$ which implies that

$$
\pi^{C}=\frac{s_{o}\left(\bar{\theta} s_{c}-A C(n)\right) A C(n)}{s_{c}^{2}(\bar{\theta}-\underline{\theta})} .
$$

Using the fact that $p^{C}>p^{c *} \Longleftrightarrow \bar{\theta} s_{c}\left(s_{o}-s_{c}\right)<\left(2 s_{o}-s_{c}\right) A C(n)$, we can easily show that $\pi^{c *}>\pi^{a *}$ and thus that accommodating copying users is more profitable.

(ii) If the other firms choose to accommodate copying users at price $p=p_{i}^{E *}$, then firm $i$ makes a larger profit by accommodating $\alpha$-reversing users at price $p^{\alpha *}\left(p_{i}^{E *}\right)$ than by accommodating copying users at price $p=p_{i}^{E *}$. On the one hand, consider again that $p_{i}^{E *}=p^{c *}$. At the price $p=p^{c *}$, firm $i$ 's optimal price and profit under accommodation of $\alpha$-reversing users are

$$
\begin{aligned}
p_{i}^{\alpha *}\left(p^{c *}\right) & =\frac{1}{4}(n+1)\left(A C(n)+\left(s_{o}-s_{c}\right) \bar{\theta}\right), \\
\pi^{\alpha *}\left(p^{c *}\right) & =\frac{\left(\left(s_{o}-s_{c}\right) \bar{\theta}+A C(n)\right)^{2}(n+1)^{2}}{16\left(s_{o}-s_{c}\right) n^{2}} .
\end{aligned}
$$

Some algebraic manipulations show that $\pi^{\alpha *}\left(p^{c *}\right)>\pi^{c *}$ and thus that accommodating $\alpha$-reversing users is more profitable. On the other hand, consider that $p_{i}^{E *}=p^{C}$. At the price $p=p^{C}$, firm $i$ 's optimal price and profit under accommodation of $\alpha$-reversing users are

$$
\begin{aligned}
p_{i}^{\alpha *}\left(p^{C}\right) & =\frac{1}{2}\left(\bar{\theta} n\left(s_{o}-s_{c}\right)+C(n)-(n-1)\left(s_{o} / s_{c}\right) A C(n)\right), \\
\pi^{\alpha *}\left(p^{C}\right) & =\frac{\left(n s_{c}\left(s_{o}-s_{c}\right) \bar{\theta}-A C(n)\left((n-1) s_{o}-n s_{c}\right)\right)^{2}}{4 n s_{c}^{2}\left(s_{o}-s_{c}\right)(\bar{\theta}-\underline{\theta})},
\end{aligned}
$$

which can also been shown to be larger than $\pi^{C}$.

\subsection{The case with high valuation users}

Best response function. There are two possible cases according to whether $\widehat{p}$ is below or above $p^{d}$. We note that $\pi_{i}^{\ell *}>\pi_{i}^{c *}$. Indeed, the optimal profit collected under demand $p_{i}^{\ell}(\theta)$ can never be smaller than the one obtained under demand $p_{i}^{c}(\theta)$ since $p_{i}^{\ell}(\theta)>p_{i}^{c}(\theta) \forall \theta \in(\underline{\theta}, \bar{\theta}]$. We now have to compare $\pi_{i}^{c *}$ with the profits under $\alpha$-reversing deterrence, $\pi_{i}^{D}(p)$ and under $\alpha$-reversing accommodation, $\pi_{i}^{\alpha *}(p)$. One can compute:

$$
\begin{aligned}
\pi_{i}^{c *} & =\frac{\left(\left(s_{o}-s_{c}\right) \bar{\theta}+C^{\prime}(n)\right)^{2}}{4\left(s_{o}-s_{c}\right)(\bar{\theta}-\underline{\theta})} \\
\pi_{i}^{D}(p) & =\frac{1}{(\bar{\theta}-\underline{\theta})} \frac{(n-1) p-C(n)}{(n-1) s_{o}-n s_{c}} s_{o}\left(\bar{\theta}-\frac{(n-1) p-C(n)}{(n-1) s_{o}-n s_{c}}\right) \\
\pi_{i}^{\alpha *}(p) & =\frac{\left(\bar{\theta} n\left(s_{o}-s_{c}\right)+C(n)-(n-1) p\right)^{2}}{4 n\left(s_{o}-s_{c}\right)(\bar{\theta}-\underline{\theta})} .
\end{aligned}
$$


Because a rise in $p$ increases the constraint on demand for loyal users $p_{i}^{\ell}$, the profit $\pi_{i}^{D}(p)$ must decrease in $p$. Also, since the demand of reversing users gets smaller when $p$ rises, the profit $\pi_{i}^{\alpha *}(p)$ must decrease in $p$. Hence, in any case, there exists a price $\widehat{p}$ above which the accommodation of copying users is profitable.

Let us derive the exact value of $\widehat{p}$. There are two possible cases according to whether $\pi_{i}^{c *}$ intersects $\pi_{i}^{D}(p)$ or $\pi_{i}^{\alpha *}(p)$. Define

$$
\pi_{i}^{d} \equiv \pi_{i}^{\alpha *}\left(p^{d}\right)=\pi_{i}^{D}\left(p^{d}\right)=\frac{n s_{o}^{2}\left(s_{o}-s_{c}\right) \bar{\theta}^{2}}{(\bar{\theta}-\underline{\theta})\left((n+1) s_{o}-n s_{c}\right)^{2}} .
$$

Now, compute the value of $C^{\prime}(n)$ such that $\pi_{i}^{c *}=\pi_{i}^{d}$ :

$$
C^{\prime}(n)=C_{0}^{\prime} \equiv \frac{\left(n s_{c}-(n+1-2 \sqrt{n}) s_{o}\right)\left(s_{o}-s_{c}\right)}{(n+1) s_{o}-n s_{c}} \bar{\theta}
$$

In the first case, $C^{\prime}(n)$ is lower than $C_{0}^{\prime}, \pi_{i}^{c *}$ is lower than $\pi_{i}^{d}$ and the price jump takes place at $\widehat{p}^{\prime}$ such that $\pi_{i}^{\alpha *}\left(\widehat{p}^{\prime}\right)=\pi_{i}^{c *}$ :

$$
\widehat{p}^{\prime}=p^{d}+\frac{\sqrt{n}}{n-1}\left[C_{0}^{\prime}-C^{\prime}(n)\right] .
$$

In the second case, $C^{\prime}(n)$ is larger than $C_{0}^{\prime}, \pi_{i}^{c *}$ is larger than $\pi_{i}^{d}$ and the price jump takes place at $\hat{p}^{\prime \prime}$ such that $\pi_{i}^{D}\left(\hat{p}^{\prime \prime}\right)=\pi_{i}^{c *}$ :

$$
\widehat{p}^{\prime \prime}=p^{d}+\frac{1}{2(n-1)}\left[F\left(C^{\prime}(n)\right)-F\left(C_{0}^{\prime}\right)\right] \text {, }
$$

where

$$
F\left(C^{\prime}(n)\right) \equiv \sqrt{\frac{\left(s_{c}\left(s_{o}-s_{c}\right) \bar{\theta}^{2}-2 C^{\prime}(n)\left(s_{o}-s_{c}\right) \bar{\theta}-C^{\prime}(n)^{2}\right)\left((n-1) s_{o}-n s_{c}\right)^{2}}{s_{o}\left(s_{o}-s_{c}\right)}} .
$$

Note that $\pi_{i}^{\ell *}>\pi_{i}^{c *}$ makes sure that $F(\cdot)$ is a well-defined function of $C^{\prime}(n)$.

Symmetric equilibria. (1) Blockading piracy cannot be a symmetric equilibrium. From Proposition 2, blockading piracy is an equilibrium if and only if $A C(n) \geq \bar{\theta} s_{c} / 2$. But, according to Assumption 5 and $6, \underline{\theta} s_{c} \geq A C(n-1)$ and $\bar{\theta}>2 \underline{\theta}+C^{\prime}(n) /\left(s_{o}-s_{c}\right)$. It is easily seen that the three inequalities cannot be simultaneously satisfied.

(2) Deterrence of $\alpha$-reversing users under good copies. We first show that under good copies, Assumption 6 implies that $C^{\prime}(n)<C_{0}^{\prime}$, so that $\widehat{p}>p^{d}$. Assumption 6 rewrites as $C^{\prime}(n)<(\bar{\theta}-2 \underline{\theta})\left(s_{o}-s_{c}\right) \equiv C_{1}^{\prime}$. Now, $C_{1}^{\prime}<C_{0}^{\prime}$ $\Longleftrightarrow\left((n+1) s_{o}-n s_{c}\right) \underline{\theta}>\left((n+1-\sqrt{n}) s_{o}-n s_{c}\right) \bar{\theta}$, which is always true if copies are good (and $n \geq 4$ ) as the right-hand side is negative.

The first condition for a symmetric equilibrium is:

$$
p_{i}^{D}\left(p^{f}\right)<p^{f} \Longleftrightarrow A C(n)<\bar{\theta} s_{c} / 2 .
$$


The second condition is either $p_{i}^{D}\left(p^{d}\right) \leq p^{d} \Longleftrightarrow p^{d} \leq A C(n)\left(s_{o} / s_{c}\right) \Longleftrightarrow$ $\frac{1}{2} \bar{\theta}\left(1-\frac{n s_{c}-(n-1) s_{o}}{(n+1) s_{o}-n s_{c}}\right) \leq A C(n) / s_{c}$. It is easily checked that the interval defined by the two conditions is open.

(3) Accommodation of $\alpha$-reversing users. This strategy is feasible if and only if $C^{\prime}(n)<C_{0}^{\prime}$, under which $\widehat{p}=\widehat{p}^{\prime}<p^{d}$. In this case, there are two conditions for a symmetric equilibrium. We first need that $p^{d} \leq p_{i}^{D}\left(p^{d}\right)$. That is,

$$
A C(n) \leq \frac{1}{2} \bar{\theta} s_{c}\left(1-\frac{n s_{c}-(n-1) s_{o}}{(n+1) s_{o}-n s_{c}}\right) .
$$

Second, we need that $\widehat{p}^{\prime} \geq p_{i}^{\alpha *}\left(\widehat{p}^{\prime}\right)$. To simplify computations, we prefer to use the equivalent formulation: at $p=p_{i}^{\alpha *}(p)$, we have that $\pi_{i}^{\alpha *}(p) \geq \pi_{i}^{c *}$. We compute

$$
\begin{aligned}
p & =p_{i}^{\alpha *}(p) \Longleftrightarrow p=\frac{\bar{\theta}\left(s_{o}-s_{c}\right)+C(n)}{n+1} \\
\pi_{i}^{\alpha *}(p) & \geq \pi_{i}^{c *} \Longleftrightarrow \bar{\theta} n\left(s_{o}-s_{c}\right)+C(n)-(n-1) p \geq \sqrt{n}\left(\left(s_{o}-s_{c}\right) \bar{\theta}+C^{\prime}(n)\right),
\end{aligned}
$$

which gives

$$
\widehat{p}^{\prime} \geq p_{i}^{\alpha *}\left(\widehat{p}^{\prime}\right) \Longleftrightarrow A C(n) \geq \frac{(n+1) \sqrt{n}-2 n}{2 n} \bar{\theta}\left(s_{O}-s_{c}\right)+\frac{(n+1) \sqrt{n}}{2 n} C^{\prime}(n)
$$

Let us check that the conditions (8) and (9) are compatible. They define an open interval if

$$
C^{\prime}(n)<\frac{2 n}{(n+1) \sqrt{n}}\left(\frac{1}{2} \bar{\theta} s_{c}\left(1-\frac{n s_{c}-(n-1) s_{o}}{(n+1) s_{o}-n s_{c}}\right)-\frac{(n+1) \sqrt{n}-2 n}{2 n} \bar{\theta}\left(s_{o}-s_{c}\right)\right) .
$$

where the right-hand side is just equal to $C_{o}^{\prime}$; as $C^{\prime}(n)<C_{0}^{\prime}$ in the present case, the interval is open.

(4) Accommodation of copying users. Accommodation of copying users occurs if and only if $p_{i}^{c *}$ is larger than $\widehat{p}^{\prime}$ or $\widehat{p}^{\prime \prime}$. Suppose first that $C^{\prime}(n)<C_{0}^{\prime}$. We need $p_{i}^{c *}>\widehat{p}^{\prime}$, which is equivalent to:

$$
C^{\prime}(n)>\frac{2 n}{n-1+2 \sqrt{n}} A C(n)+\frac{n-1+2 \sqrt{n}}{n+1-2 \sqrt{n}} \bar{\theta}\left(s_{o}-s_{c}\right),
$$

which is clearly impossible because $C^{\prime}(n)<A C(n)$ by Assumption 1 and $2 n /(n-1+2 \sqrt{n})>1$. Consider next the case where $C^{\prime}(n)>C_{0}^{\prime}$. We need $p_{i}^{c *}>\widehat{p}^{\prime \prime}$, which is equivalent to:

$$
A C(n)<\frac{1}{2 n} \bar{\theta} s_{c}+\frac{n-1}{2 n} C^{\prime}(n)-\frac{F\left(C^{\prime}(n)\right)}{2 n} .
$$

The latter inequality is compatible with $C^{\prime}(n) \leq A C(n)$ if and only if

$$
(n+1) C^{\prime}(n)+F\left(C^{\prime}(n)\right)<\bar{\theta} s_{c},
$$

which cannot be excluded by our assumptions. 